\title{
Investigation of Seal-to-Floor Effects on Semi-Span Transonic Models
}

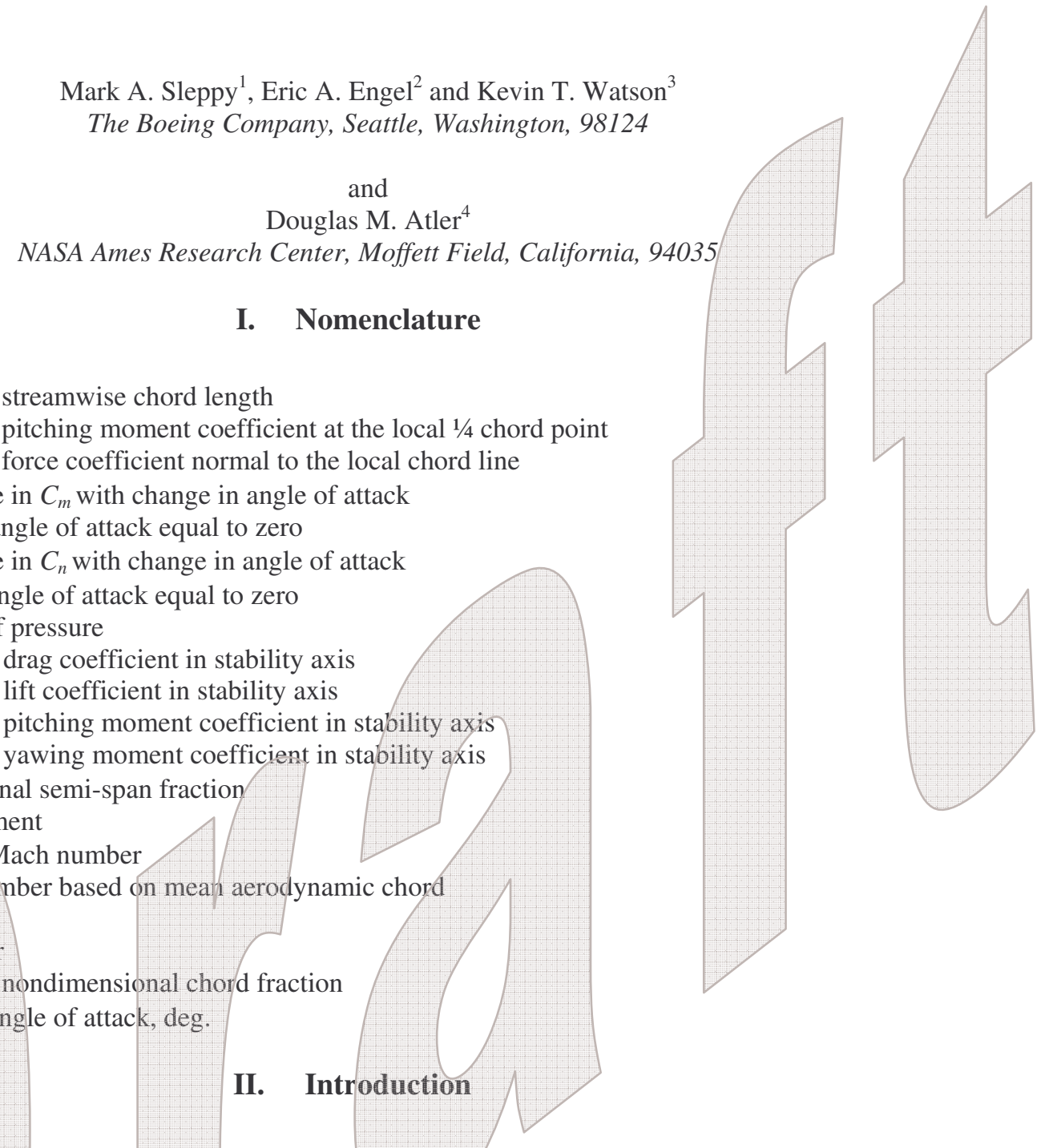

$c=$ local section streamwise chord length

$C_{m}=$ local section pitching moment coefficient at the local $1 / 4$ chord point

$C_{n}=$ local section force coefficient normal to the local chord line

$C_{m \alpha}=$ linear change in $C_{m}$ with change in angle of attack

$C_{m o}=$ linear $C_{m}$ at angle of attack equal to zero

$C_{n \alpha}=$ linear change in $C_{n}$ with change in angle of attack

$C_{n o}=$ linear $C_{n}$ at angle of attack equal to zero

$C_{p}=$ coefficient of pressure

$C_{D S A}=$ total balance drag coefficient in stability axis

$C_{L S A}=$ total balance lift coefficient in stability axis

$C_{P M S A}=$ total balance pitching moment coefficient in stability axis

$C_{Y M S A}=$ total balance yawing moment coefficient in stability axis

$E T A=$ nondimensional semi-span fraction

$M \quad=\quad$ bending moment

$M_{\infty}=$ free stream Mach number

$\operatorname{Re}=$ Reynolds number based on mea 1 aerodynamic chor

$T=$ torsion

$V=$ vertical shear

$x o c=$ local section nondimensional chord fraction

$\alpha=$ free stream angle of attack, deg.

II. Introduction

Tn an effort to achieve the maximum possible Reynolds number (R.e) when conducting production testing for flight

loads aerodynamic databases, it has been the preferred practice of The Boeing Company / Commercial Airplanes -

Loads (BCA) and Dynamics Group since the early 1990's to test large scale semi-span models in the 11-By 11-Foot

Transonic Wind Tunnel (TWT) leg of the Unitary Plan Wind Tunnel (UPWT) at the NASA Ames Research Center.

There are many problems related with testing large scale semi-span models representing high aspect ratio flexible

transport wings (Fig. 2a), such as; floor boundary layer effects, wing spanwise wall effects, solid blockage buoyancy

\footnotetext{
${ }^{1}$ Associate Technical Fellow, BCA Structures, Loads \& Dynamics, P.O. Box 3707 MS 03-KT, AIAA Member.

${ }^{2}$ Engineer, BCA. Structures, Loads \& Dynamics, P.O. Box 3707 MS 03-KT.

${ }^{3}$ Principal Engineer, BCA ANPSDL, Aero Test Methods and Tech, P.O. Box 3707 MS 1W-82, AIAA Member.

${ }^{4}$ Test Engineer, Wind Tunnel Operations Branch, MS 227-5.
} 
effec7ts, floor mechanical interference effects, airflow under the model effects, or tunnel flow gradient effects ${ }^{1}$. For most of these issues, BCA has developed and implemented either standard testing methods or numerical correction schemes and these will not be discussed in this document. Other researchers have reported on semi-span transonic testing correction issues ${ }^{2,3}$, but most of the reported research has been for low Mach testing. Some of reports for low Mach testing address the difficult problem of preventing undesirable airflow under a semi-span model while ensuring unrestricted main balance functionality ${ }^{4,5}$, however, for transonic models this issue has gone unresolved. BCA has been cognizant for sometime that there are marked differences in wing pressure distributions from semispan transonic model testing than from full model or flight testing (Fig.1). It has been suspected that these differences are, at least in part, due to airflow under the model. Previous efforts by BCA to address this issue have proven to be ineffective or inconclusive and in one situation resulted in broken hardware.

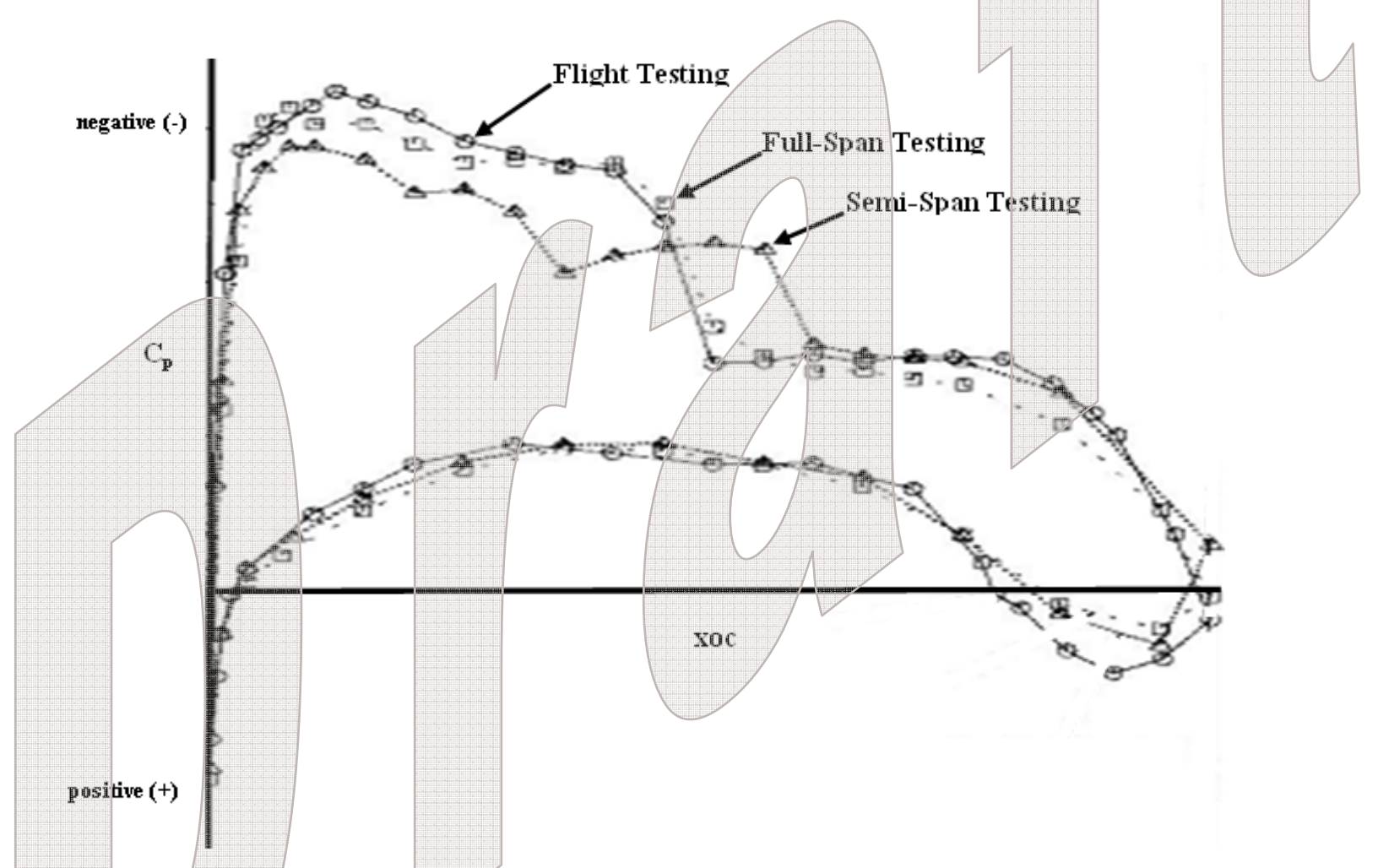

Fig. 1 Wing mid-span local section $C_{p}$ distributions verses xoc from flight, full-span and semi-span testing.

This paper reports on a Boeing-NASA collaborative investigation based on a series of small tests conducted between June 2006 and November 2007 in the 11-By 11-Foot Transonic Wind Tunnel at NASA Ames on three large commercial jet transport configurations to assess the effects of sealing a semi-span model to the floor and to investigate efficient sealing and testing techniques. These tests included 1) sealing the full perimeter of all three moders at a number of fixed angles of attack (alphas) with aluminum high speed tape, 2) sealing a model of 
configuration B with a pneumatically inflatable bulb seal system, 3) and sealing a model of configuration C with a second generation pneumatically inflatable bulb seal system.

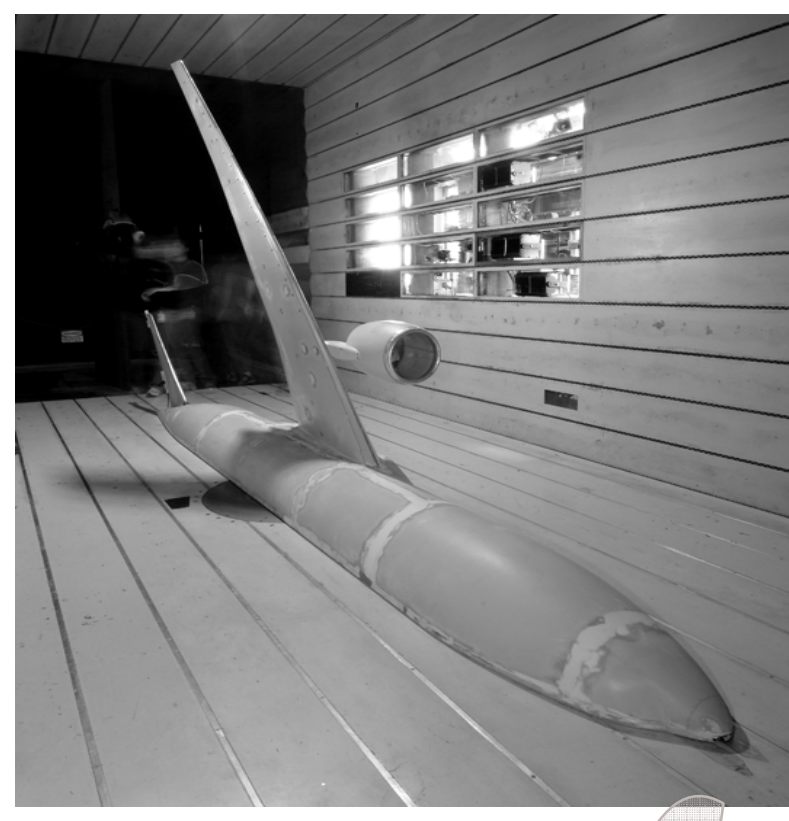

a)

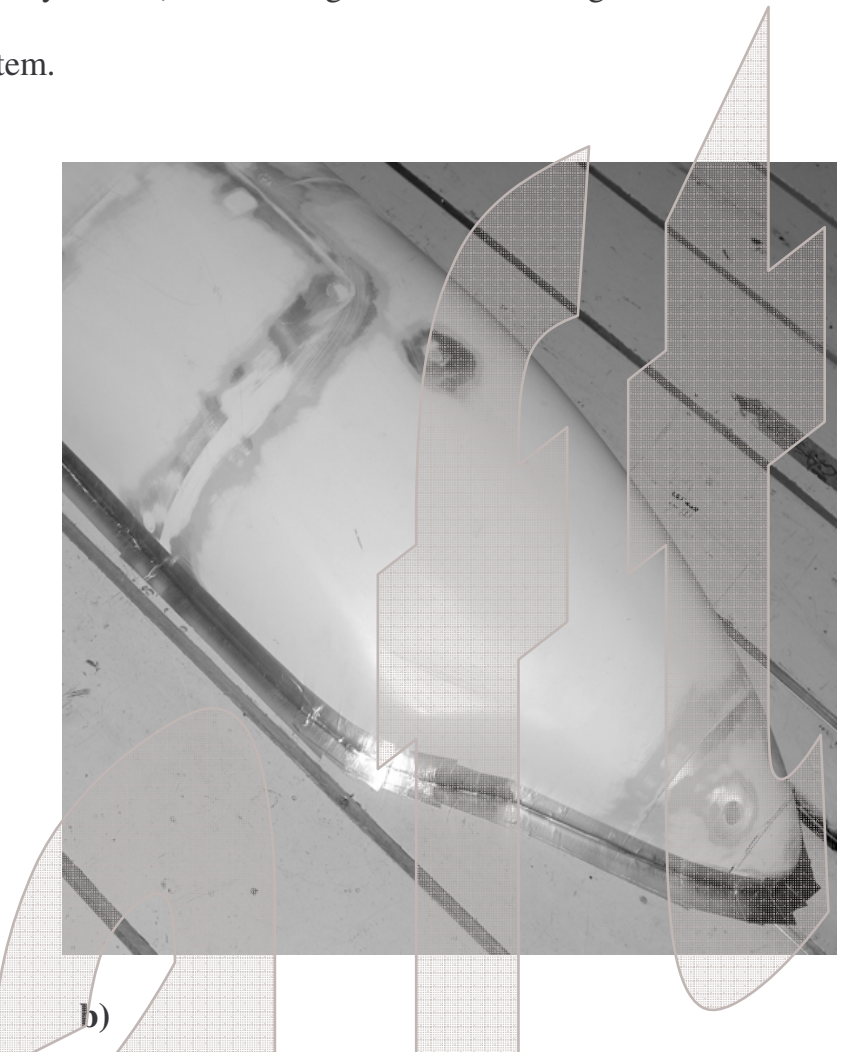

Fig. 2 a) A typical Boeing semi-span model installation in the 11-By 11-Ft TWT at the NASA Ames Research Center and b) a semi-span model sealed to the floor with alumina migh speed tape.

This document will show how sealing the model to the floor has a small but remarkably far reaching spanwise effect on wing pressures, wing local section forces and wing force/summations. This is a potentially important piece of the puzzle in deriving increased accuracy for full scale flight loads aerodynamic databases from testing in the 11By 11-Foot TWT at NASA Ames.

\section{Testing and Results}

The standard setup developed by The Boeing Company / Commercial Airplanes for restricting airflow between a semi-span model and the floor is the installation of a combination gap filler profile plate and keel dam (Fig. 3a.). This installation must/not allow the model to contact the floor and thereby foul the main balance, which is located under the floor. This requires that a small gap be maintained between the model and the floor throughout the testing envelope, but this gap ( 0.01 inches) still allows some air flow under the model. Even though previous testing suggested that the resulting flow from this small gap was insignificant ${ }^{1}$, there continued to be concern that the difference in the inboard wing pressures was due to this flow. 


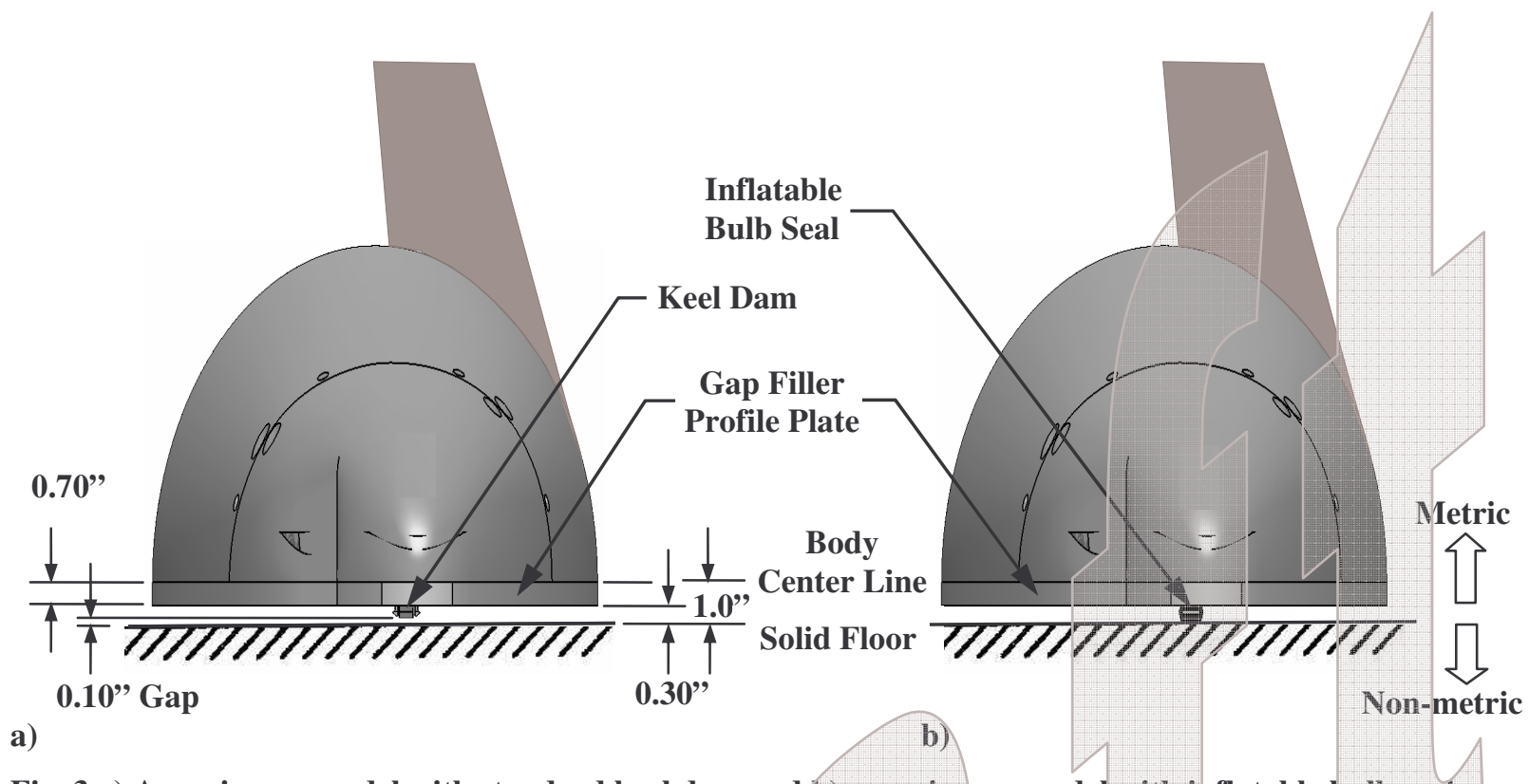

Fig. 3 a) A semi-span model with standard keel dam and b) a semi-span model with inflatable bulb seal.

\section{A. Test Facility}

The Unitary Plan Wind Tunnel (UPWT) consists of three tunnel legs: the 11-By 11-Foot TWT, the 9- by 7 Foot Supersonic Wind Tunnel, and the 8- by 7-Foot Supersonic Wind Tunnel (Fig. 4). The two supersonic legs share a common 11-stage axial-flow compressor and aftercooler/drive leg, and they use diversion valves at the ends of a common drive leg. A three-stage axial-flow compressor drives the 11-By 11-Foot TWT. A common drive motor system can be coupled to either the 3-stage or 11-stage compressor. One tunnel can therefore be run while test articles are being installed in or removed from the other two.

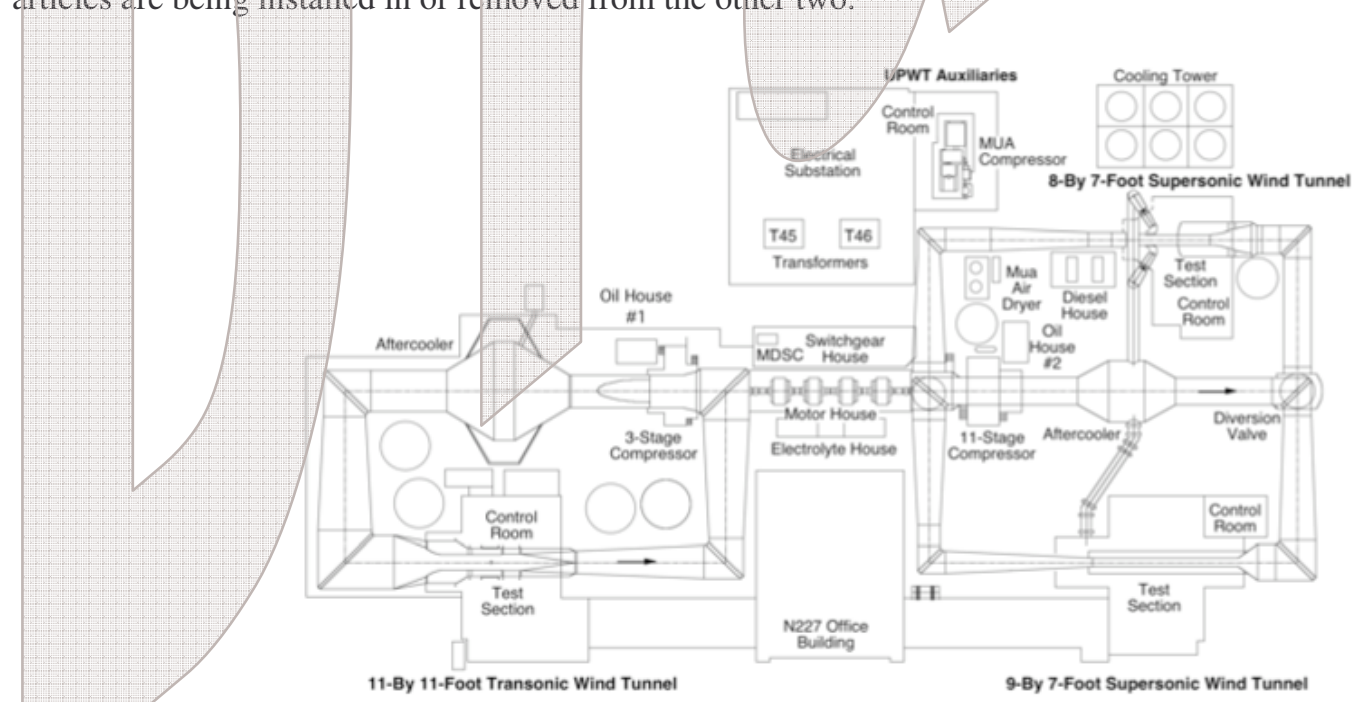

Fig. 4 Unitary Plan Wind Tunnel (UPWT) At the NASA Ames Research Center. 


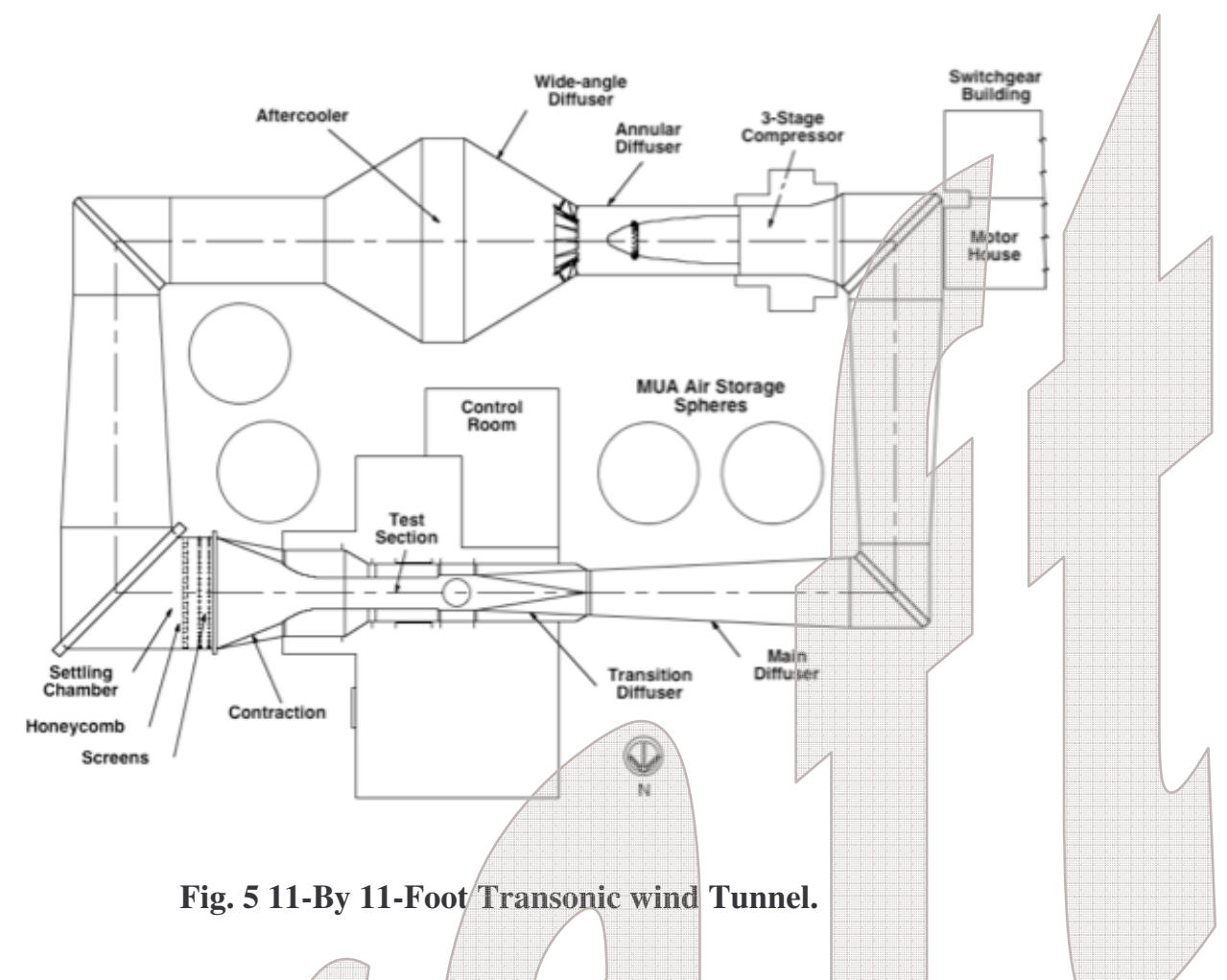

The 11-By 11-Foot TWT leg is a closed-circuit, variable-pressure, continuous operation wind tunnel (Fig.5). Subsonic Mach number control involves setting the compressor drive speed to one of ten setpoints and using variable-camber inlet guide vanes for fine Mach number control.S Supersonic Mach number control involves setting the flexible wall nozzle to achieve the proper area ratioin addition to setting the compressor drive speed and the inlet guide yanes. A tandem diffuser system with an annular diffuser followed by a wide-angle diffuser is upstream of a 70-ft-diameter aftercooler section in the drive leg. Flow-smoothing vanes are located in the tandem diffuser to improve flow uniformity entering the heat exchanger and temperature uniformity in the test section. The settling chamber upstream of the contraction is 38 feet in diameter. A Turbulence Reduction System (TRS) located in the settling chamber includes a 1 -in. cell diameter, 20-in. long honeycomb for flow straightening followed by two 0.041 -in. diameter wire, 6-mesh screens for turbulence reduction. The contraction provides a transition from the circular cross section of the settling chamber to the square cross section of the test section. The contraction ratio is 9.4. The test section is 11-By 11 -feet in cross section and 22 feet in length. Slots in all four walls run the full length of the test section. The slots contain baffles that provide a 6-percent porosity into the plenum chamber. Ejector flaps on all four walls at the exit of the test section can be set remotely to control the plenum flow bypassed from the test section. Flow exits the test section and enters a transition region back to the circular main diffuser. A Plenum 
Evacuation System (PES) provides an active method of removing air from the test section plenum by using the Make-Up Air compressor system (MUA) of the auxiliaries' facility.

\section{1-By 11-Foot TWT Turntable Support System}

The Turntable Support (TTS) System provides the capability to position semi-span models at pitch angles ranging from $+/-180$ degrees of rotation to the air flow, at pitch rates from 0.1 to $5 \mathrm{deg} / \mathrm{sec}$ with an accuracy within +/-.05 degrees. Dual resolvers provide angle measurement to within +/-0.01 degrees. The TTS ytilizes an 123 amp35.7 Hp servomotor with a 500:1 gear box. The model support is designed to support torque loads (pitch loads for semi-span models) of $+/-500,000$ in-lbs. The TTS is controlled by a closed loop Acutronic single axis controller and is remotely operated by the tunnel facility control system. The center of the TTS is located at tunnel station 106 (inches).

\section{B. Initial Taped Test (Configuration A)}

In an initial effort to determine the extent to which undesirable airflow under the model affects the pressure distribution on the wing, in June of 2006 during a production test of configuration A, the semi-span model was sealed to the floor around the full perimeter of the model with/aluminum high speed tape (Fig. 2b). A series of runs were made for a small number of fixed alphas (3), Mach numbers (3) and Reynolds numbers (2).

The results of this initial test showed that sealing the model to the floor significantly changed the pressure field on the wing. Specifically, the change in local section coefficient of pressure $\left(\mathrm{C}_{\mathrm{p}}\right)$ distribution (Fig. 6) was most noticeable on the wing upper surface at Mach numbers $(>0.80)$ and aiphas with well defined shocks. A cursory analysis of this data indicated that this change could amount to an increase of the inboard wing lift slope by as much as $2.5 \%$ with the effect becoming imperceptible by mid-spanl.
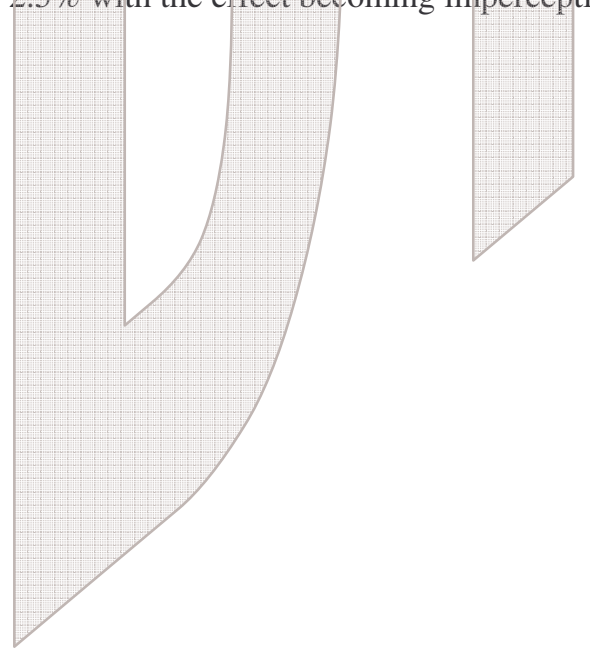

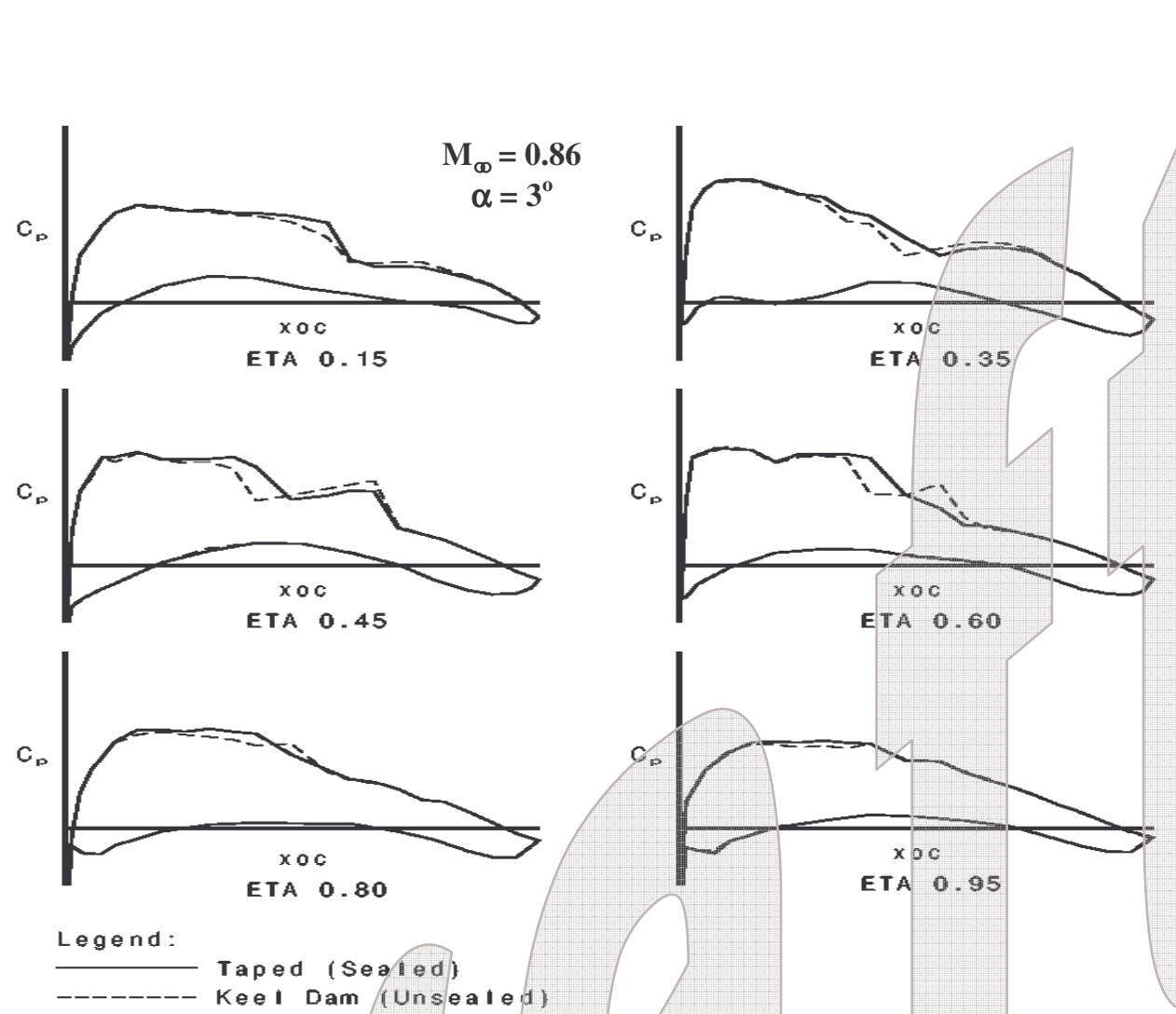

TA 0.60

Fig. 6 Speed tape and keel dam wing local section $C_{p}$ distributions verses xoc.

These results suggested the need for more testing. However, taping a model to the floor was not a practical method for preventing air flow under the model during production testing for flight loads aerodynamic databases since it was extremely time consuming to setup each alpha and did not aillow for the collection of meaningful main balance data. A more $\mathrm{useful} \mathrm{method} \mathrm{was} \mathrm{required} \mathrm{for} \mathrm{a} \mathrm{more} \mathrm{complete} \mathrm{determination} \mathrm{of} \mathrm{the} \mathrm{effects} \mathrm{throughout} \mathrm{the}$ full testing envelope and for this it was decided to develop a pneumatically inflatable bulb seal that would fit in the existing keel dam tracks on the gap filler profile plate (Fig. 3b and 7). 


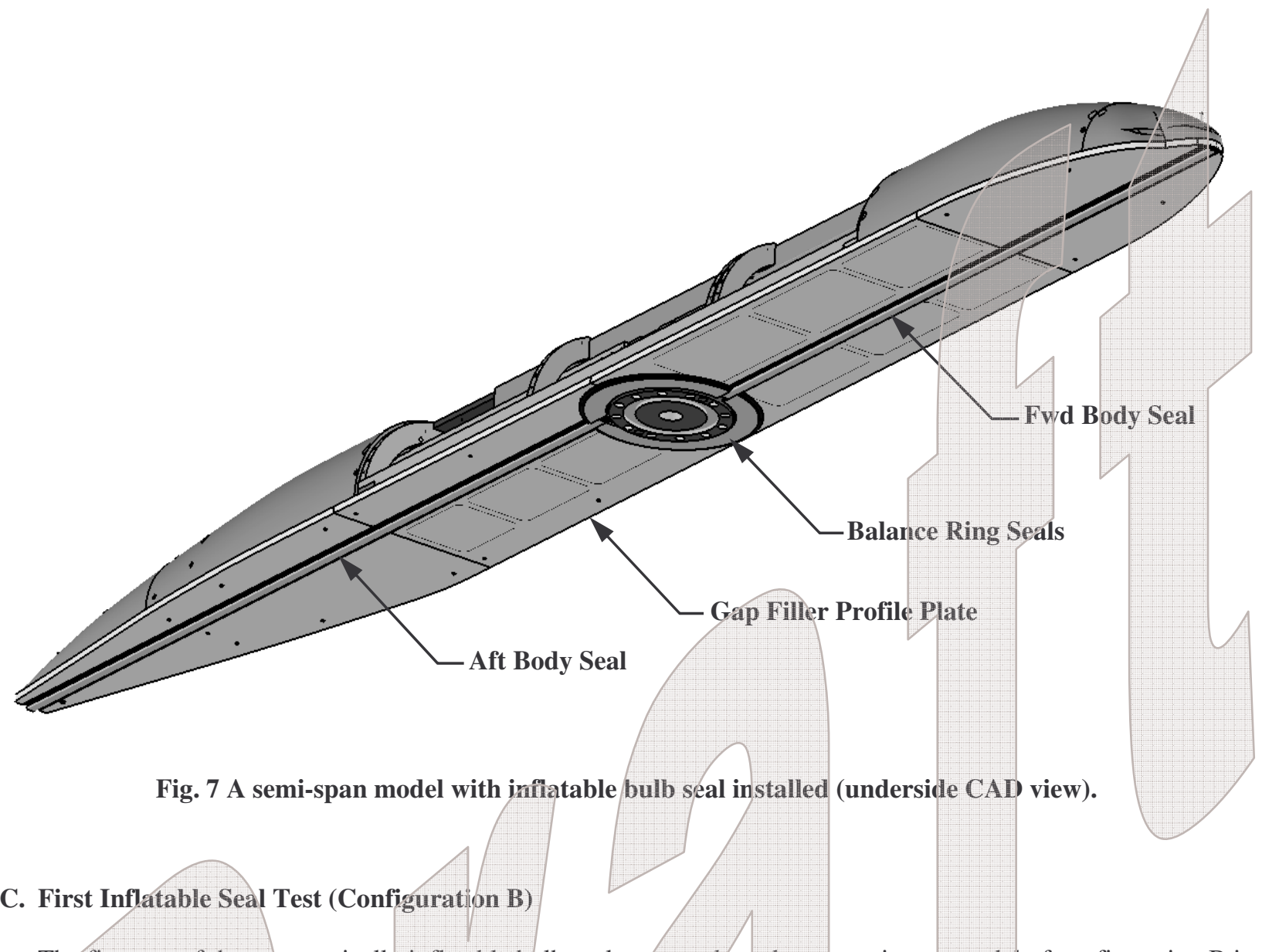

The first test of the pneumatically inflatable bulb seal was conducted on a. semi-span model of configuration B in February 2007 at the end of a previously scheduled research test. In this test, two series, one high Re and one low Re, were conducted with this seal installed for a limited Mach (8) and alpha ( 20) set, two equivalent series were conducted with standard keel dam installed and one series was condacted at high Re with full perimeter speed tape that had three Mach numbers at one alpha only.

Results from this test showed a comparable effect on the local section $\mathrm{C}_{\mathrm{p}}$ distribution when sealing the model to the floor with the pneumatically inflatable bulb seal as was seen in the earlier test when sealing with speed tape (Fig.

8). The one taped series that was conducted in this test, regretfully, provided limited data but did confirm, in this one instance, that the inflatable bulb sear worked as well as the full perimeter speed tape (Fig. 9). 

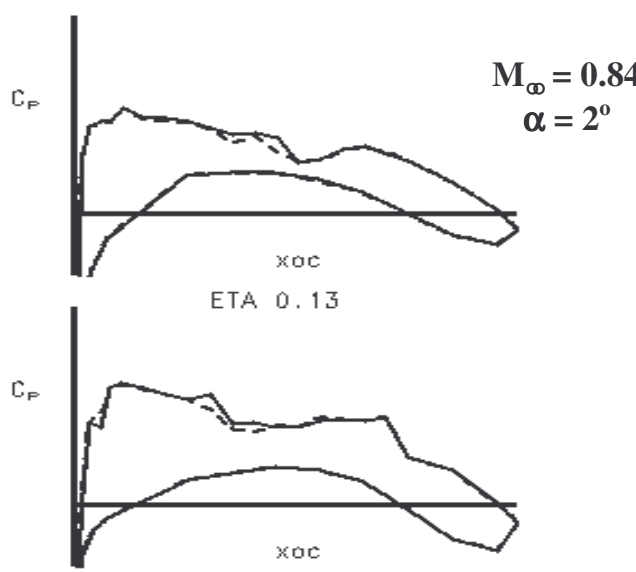

ETA 0.40

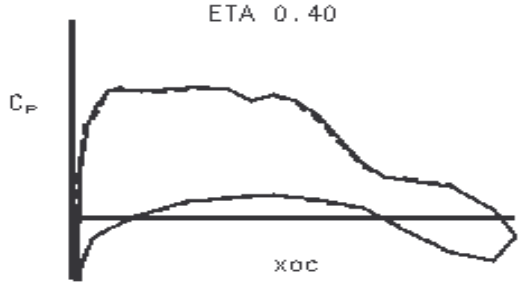

ETA 0.80

L eggend:

Eulb 5eal (5ealedy keel [ram (Unserled)

Fig. 8 Inflatable bulb seal and keel dam wing local section $C_{p}$ distributions verses xoc.
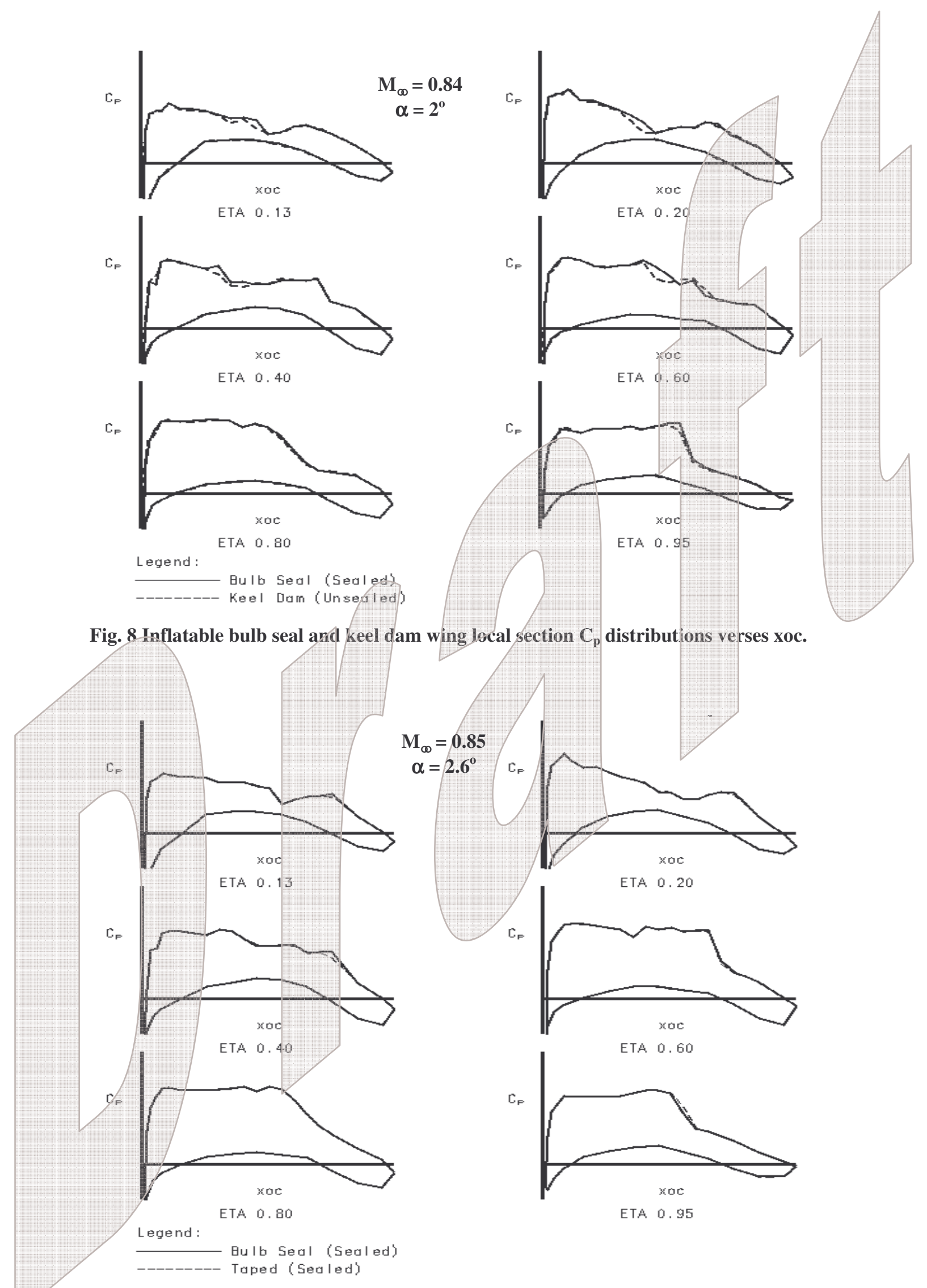

Fig. 9 Inflatable bulb seal and speed tape wing local section $C_{p}$ distributions verses xoc. 
The data from the inflatable bulb seal series were integrated into wing local section normal force coefficient $\left(C_{n}\right)$ and pitching moment coefficient about the local quarter chord $\left(\mathrm{C}_{\mathrm{m}}\right)$ and compared to the integrated data from the standard keel dam series. These span load distributions show at a given alpha with the model sealed to the floor a small increase in the $C_{n}$ on the inboard wing that tapers away to no effect about three quarter span (Fig. 10a). The $\mathrm{C}_{\mathrm{m}}$ change with the seal is not so clearly delineated but does taper off at about three quarter span (Fig. 106).
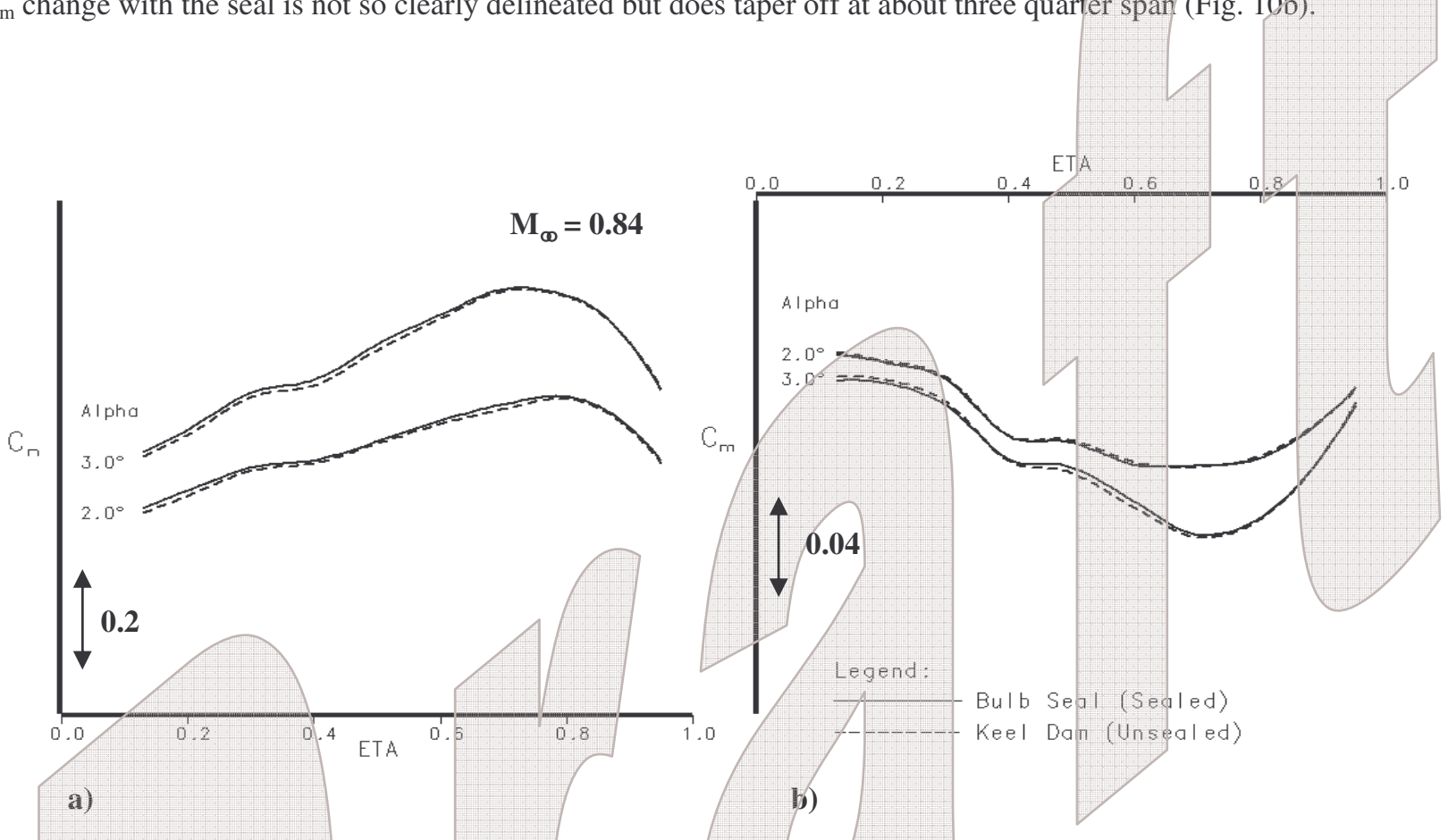

Fig. 10 a) Sealed and unsealed section normal force and b) pitching noment coefficient verses ETA.

The integrated sectional data verses alpha (Fig. 11a and $11 \mathrm{~b}$ ) were/reduced still further to $C_{n}$ and $C_{m}$ slope (Fig. 12a and 12b) and intercept coefficients (Fig. 13a and 13b). These linearized data were numerically corrected (rigidized) for wind tunnel model aeroelastic effects (Fig. 14a and 14b) and these data, in turn, were used in a static aeroelastic analysis of the full scale configuration B airframe to derive wing load distributions of vertical shear, bending monent and torsion. The change due to sealing to the floor on the resulting wing load distributions is small but extends over the entire wing span (Fig.15a, 15b and 15c). 


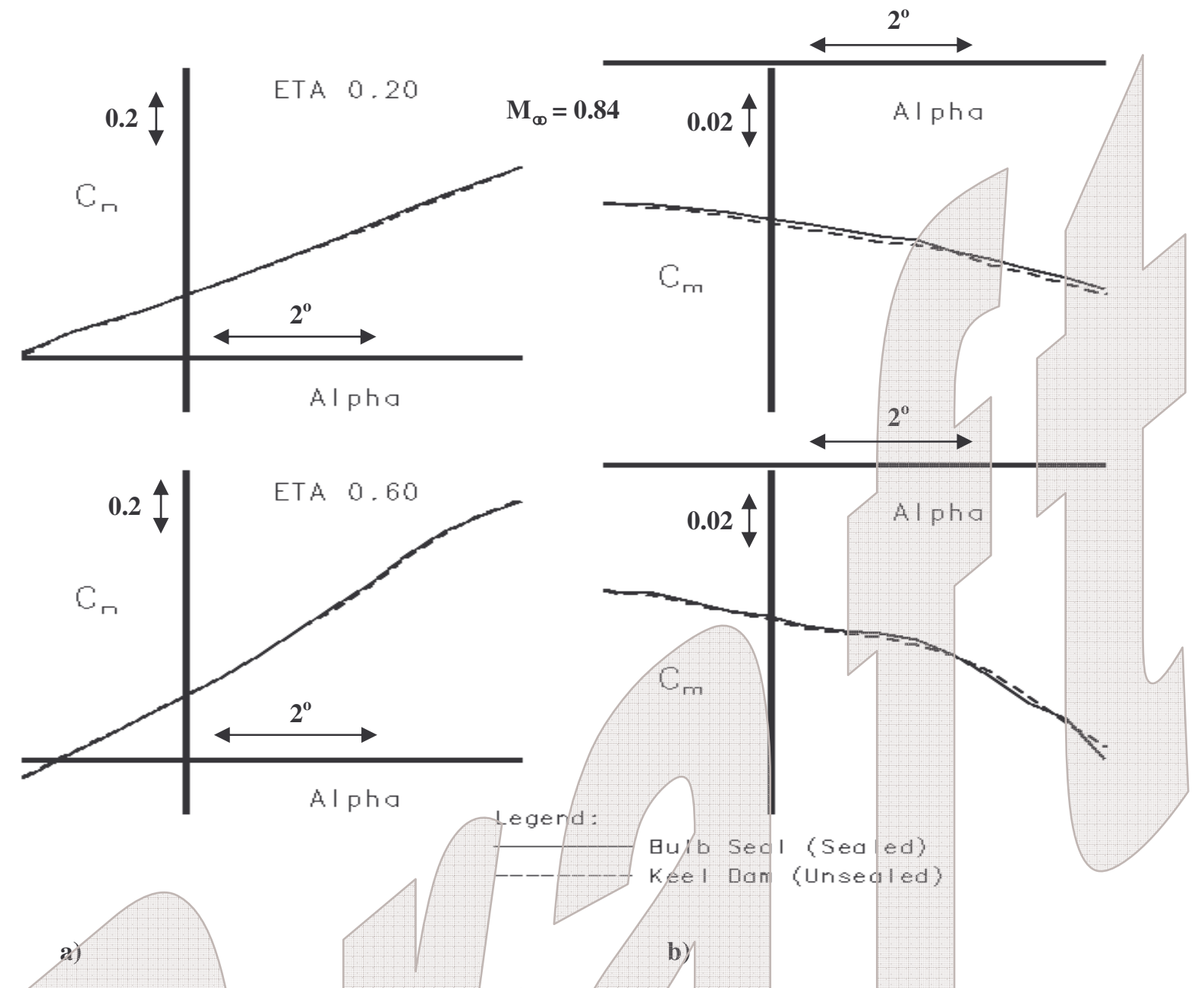

Fig. 11 a) Sealed and unsealed section nomal force and b) pitching moment coefficient verses Alpha.

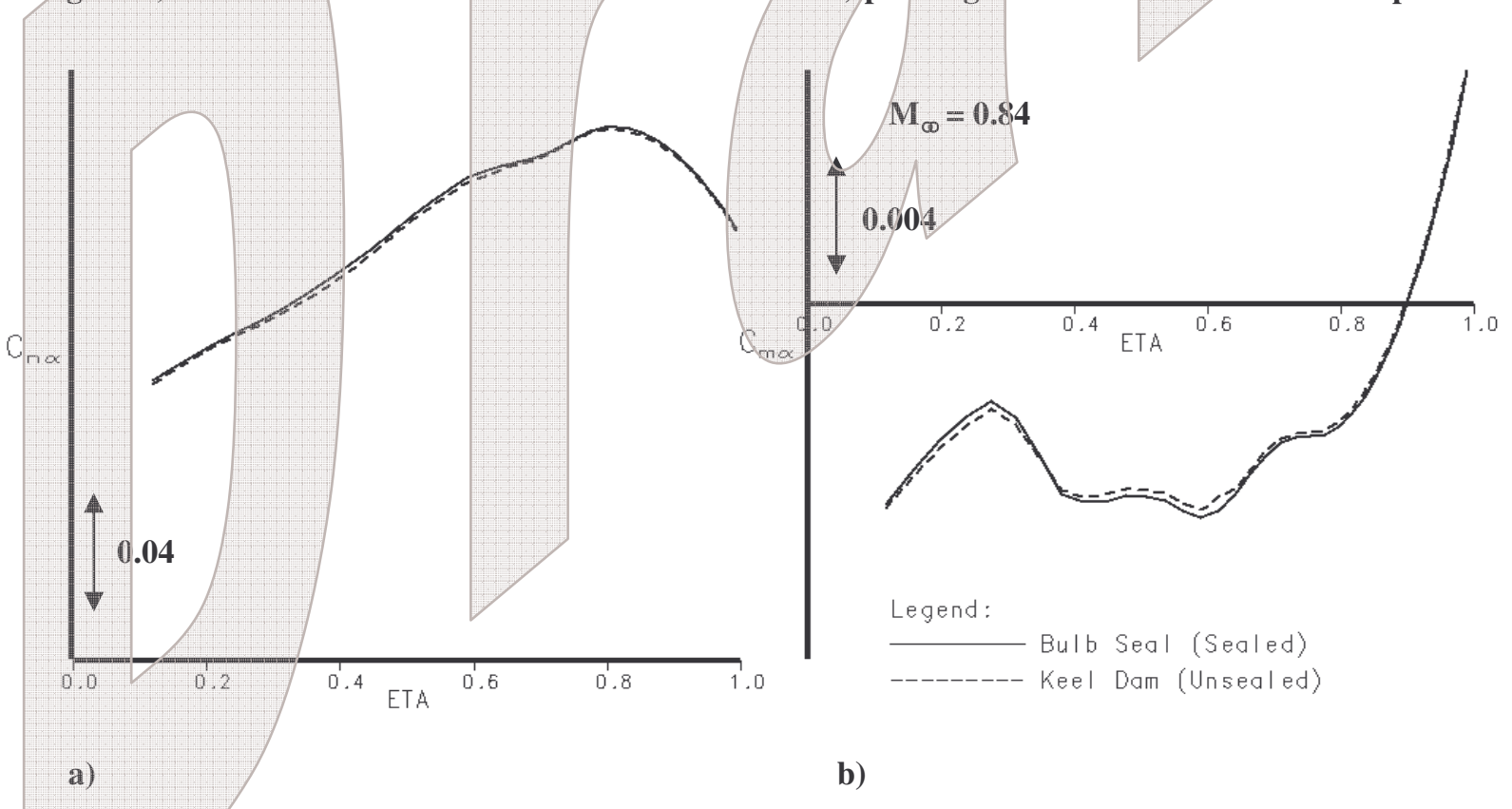

Fig. 12 a) Sealed and unsealed section normal force and b) pitching moment slope coefficient verses ETA. 


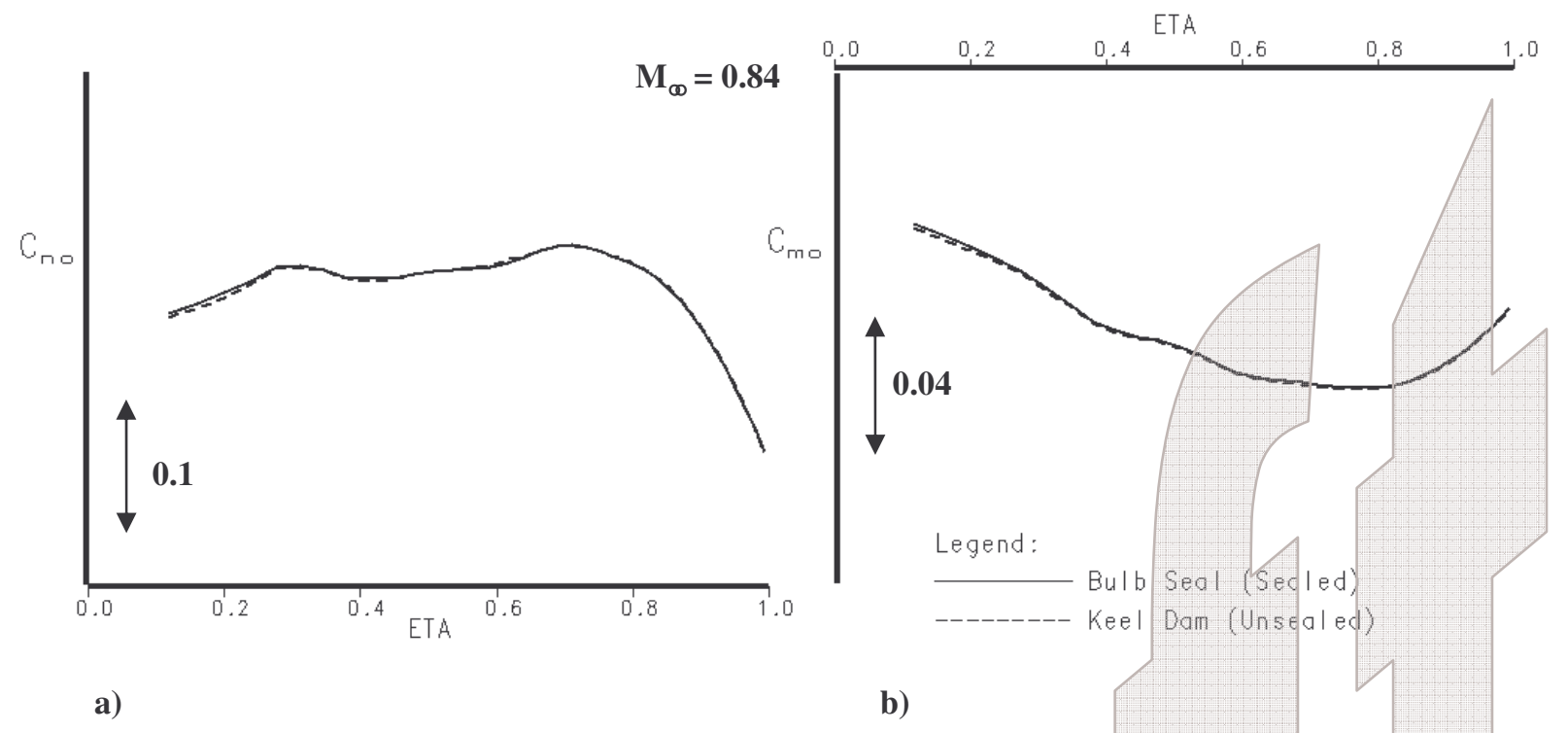

Fig. 13 a) Sealed and unsealed section normal force and b) pitching moment intercept coefficient verses ETA.

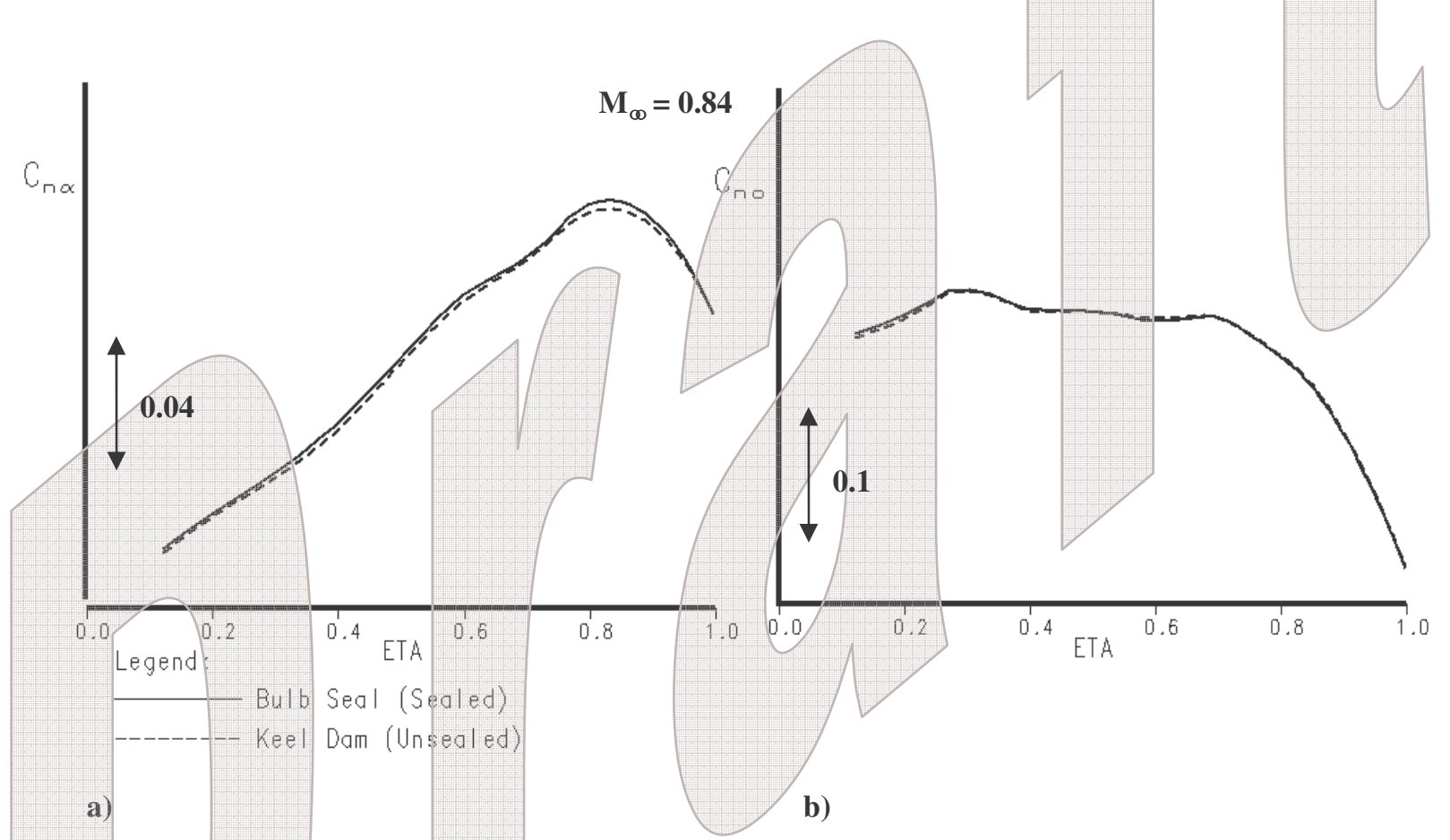

Fig. 14 a) Sealed and unsealed rigid section normal force slope and b) intercept coefficient verses ETA. 

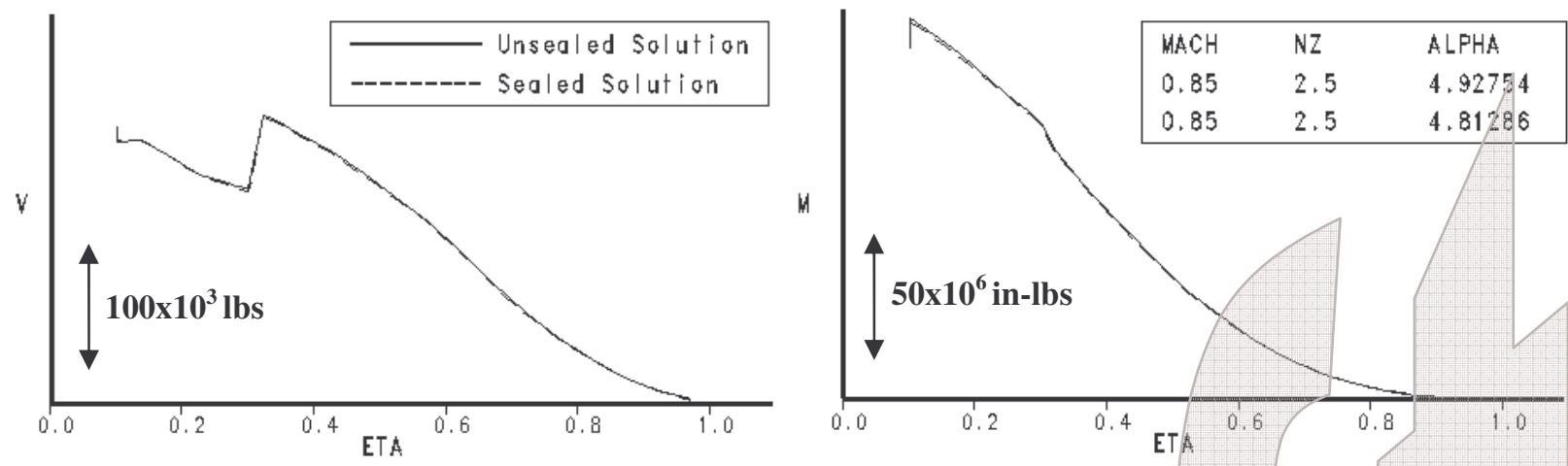

a)

b)

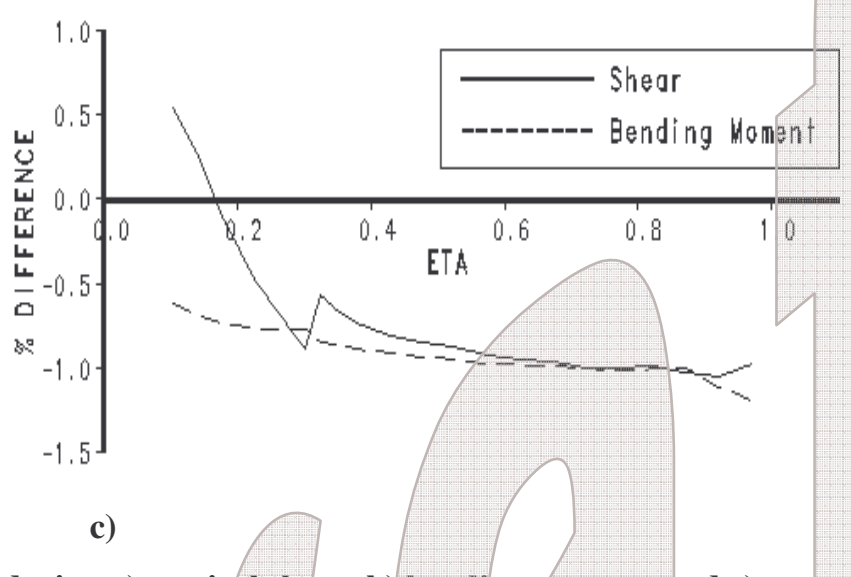

Fig. 15 Sealed and unsealed wing a) vertical shear, b) bending moment and c) percent difference verses ETA.

\section{Second Inflatable Seal Test (Configuration C)}

An improved inflatable seal system was tested on a semi-span model of configuration C in November 2007 at the end of a production test. For this test, a more comprehensive set of series were conducted with this seal installed that included a full Mach (12) and alpha ( 30) set at a high, a mid and a low Re. For comparison to these, an equivalent set of series were run with the standard keel dam installed. Furthermore, one high Re and one low Re series with the full perimeter taped to the floor with a full Mach (12) set and four alphas were tested. In addition, with the seal installed, data were taken with the seal inflated and deflated, back to back, at the same alpha with intent of acquiring useful balance data with little or no parametric variation other than the seal state.

Results from/this test also showed a similar effect on local section $\mathrm{C}_{\mathrm{p}}$ distributions due to sealing the model to the floor with the pneumatically inflatable bulb seal as compared to the earlier tests when sealing with either the speed tape or a bulb seal (Fig. 16). The many series run with the model taped to the floor in this test provided the best indication so far that an inflatable bulb seal worked as well as the full perimeter speed tape (Fig. 17), which was 
consistent over the entire test envelope. The inflated - deflated run comparisons show that in some instances the deflated seal inhibits flow as well as inflated (Fig. 18) but by and large the results from deflated seal series are fnore like the results from the standard keel dam setup (Fig. 19).
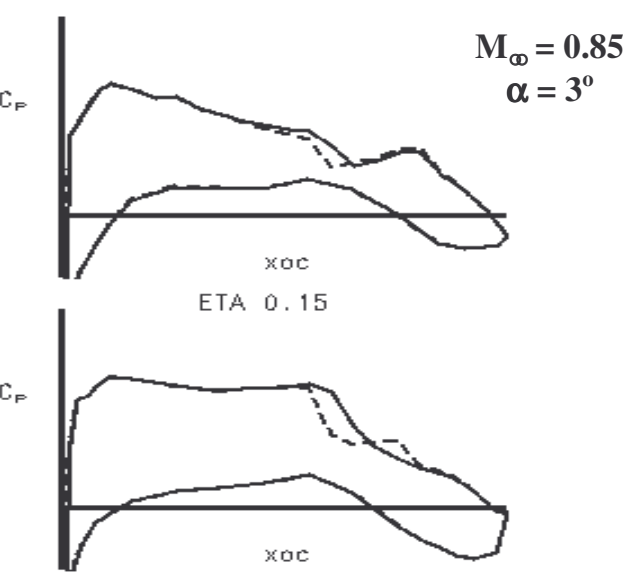

ETA 0.42
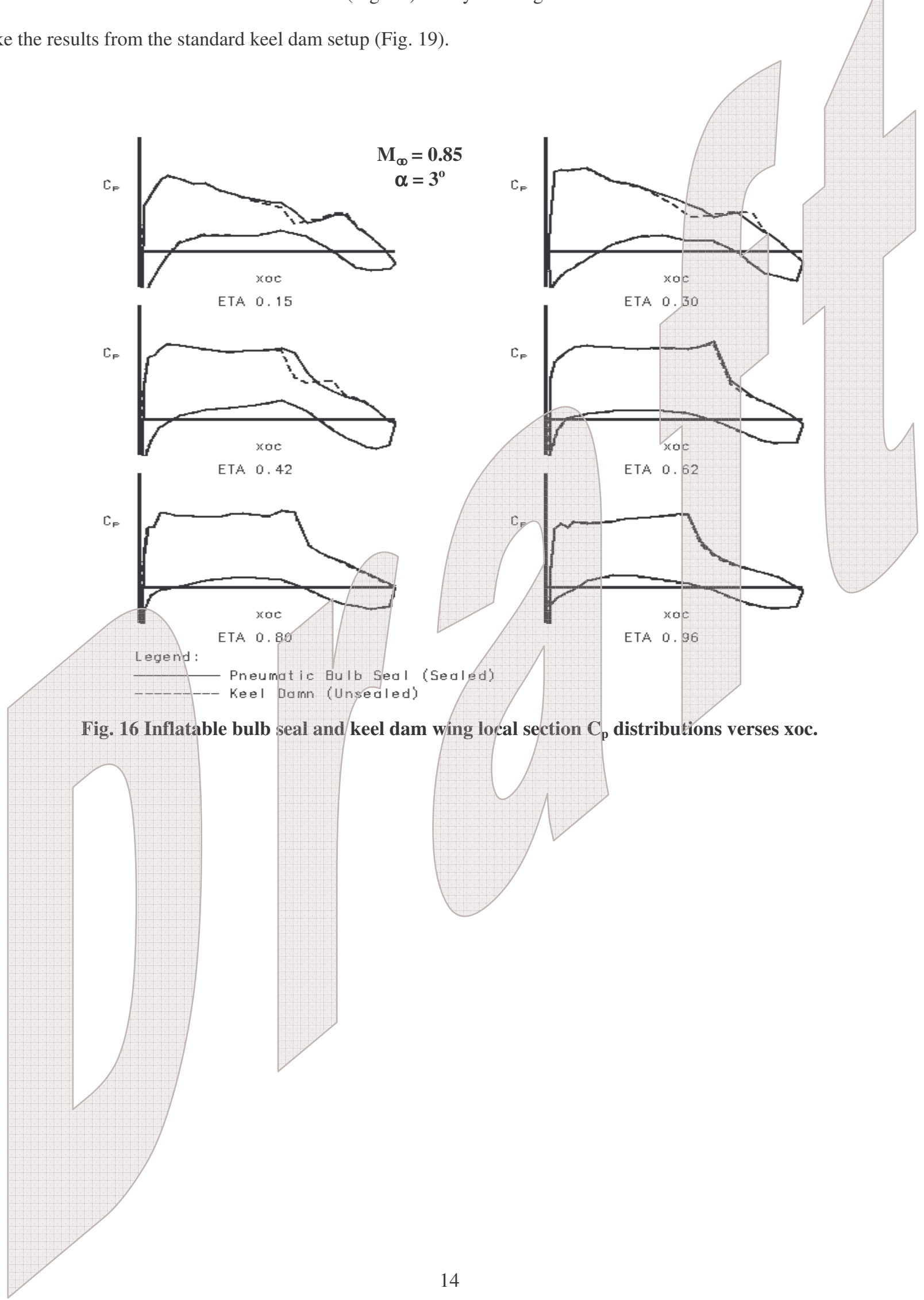

wing local section $\mathrm{C}_{\mathrm{p}}$ distributions verses xoc.
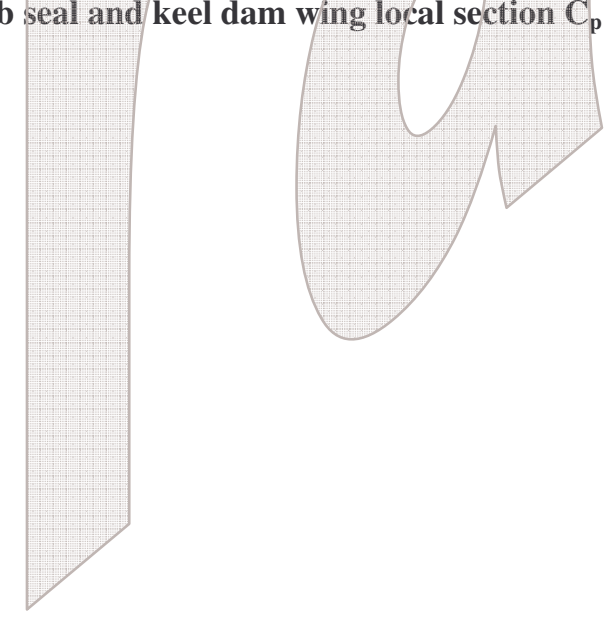

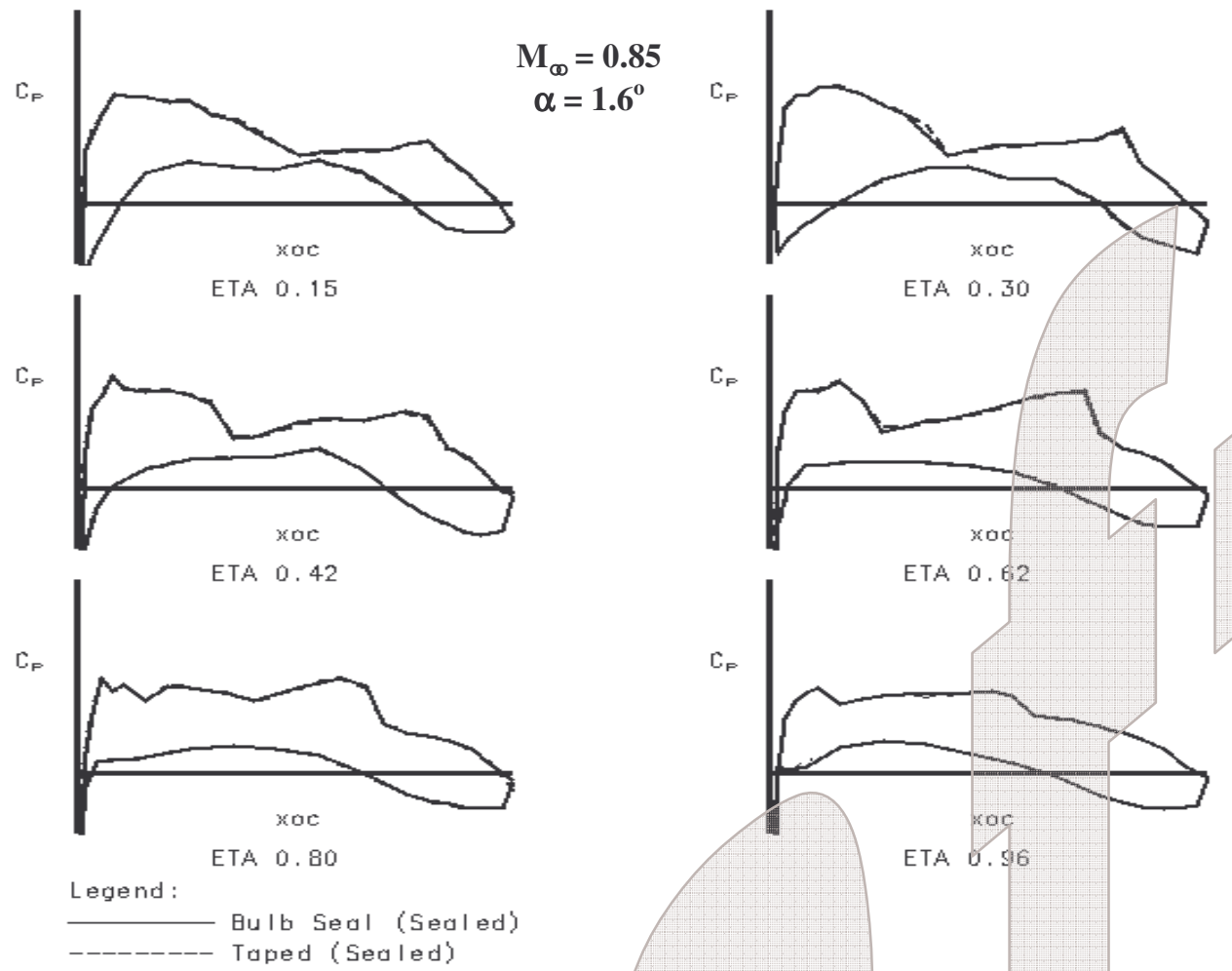

Fig. 17 Inflatable bulb seal and speed tape wing local section $C_{p}$ distributions verses xoc.

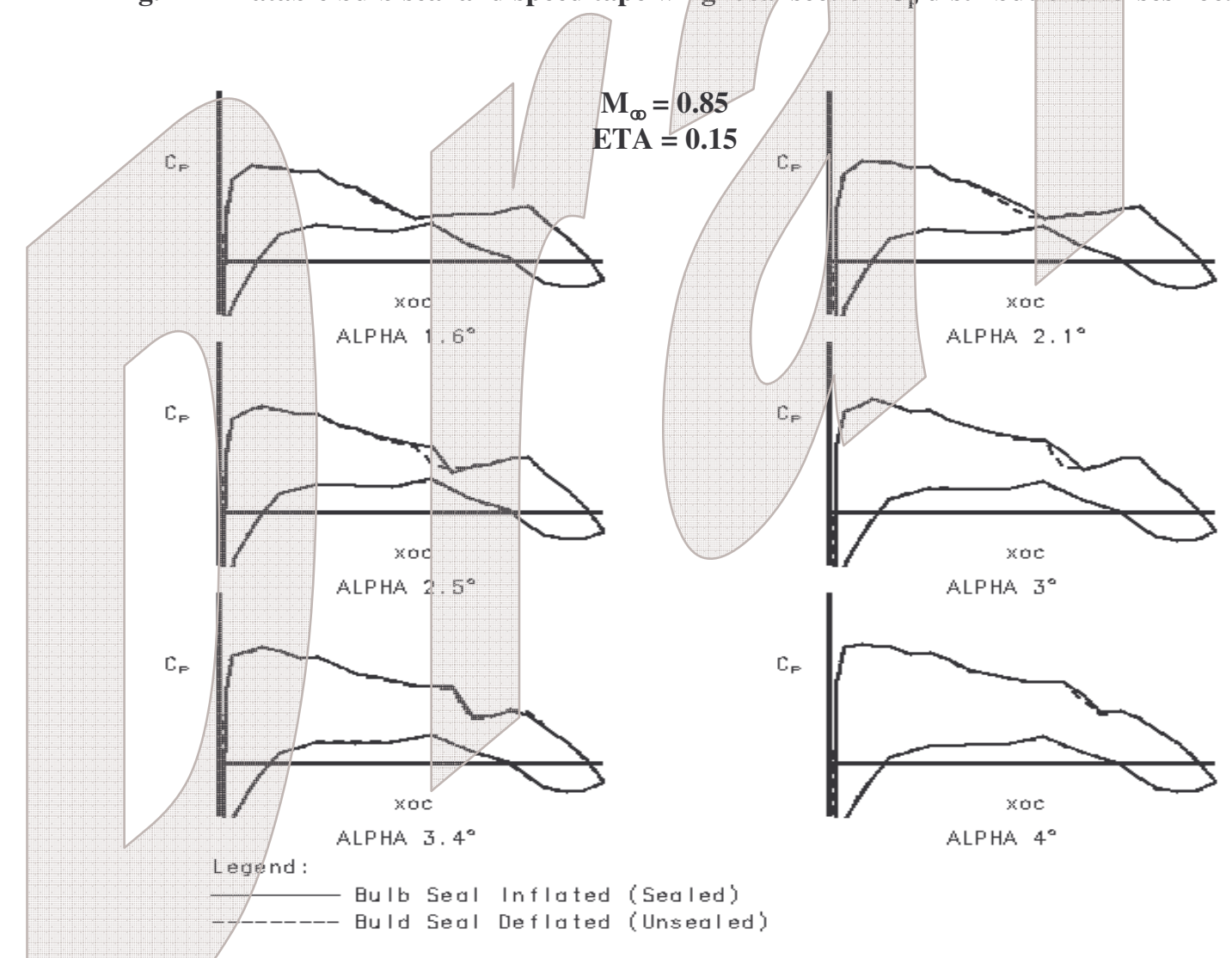

Fig. 18 Inflated and deflated bulb seal wing local section $C_{p}$ distributions verses xoc. 

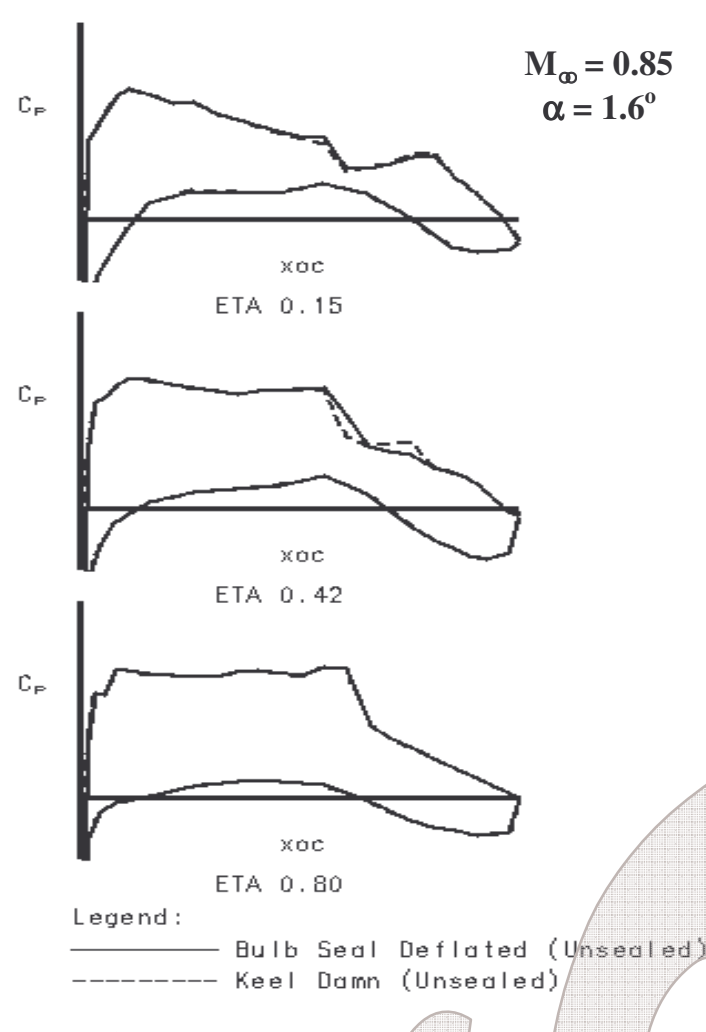

Fig. 19 Deflated bulb seal and/keel dam wing local section $C_{p}$ distributions verses xoc.

Since the tape series required the collection of data at a fixed alpha, this allowed a unique opportunity to run back to back repeats at a given Mach number. This resulted in a surprisingly large variation in the $\mathrm{C}_{\mathrm{p}}$ distribution at the shock location from one repeat to the next (Fig. 20) which is an indication of measurable, if not appreciable,
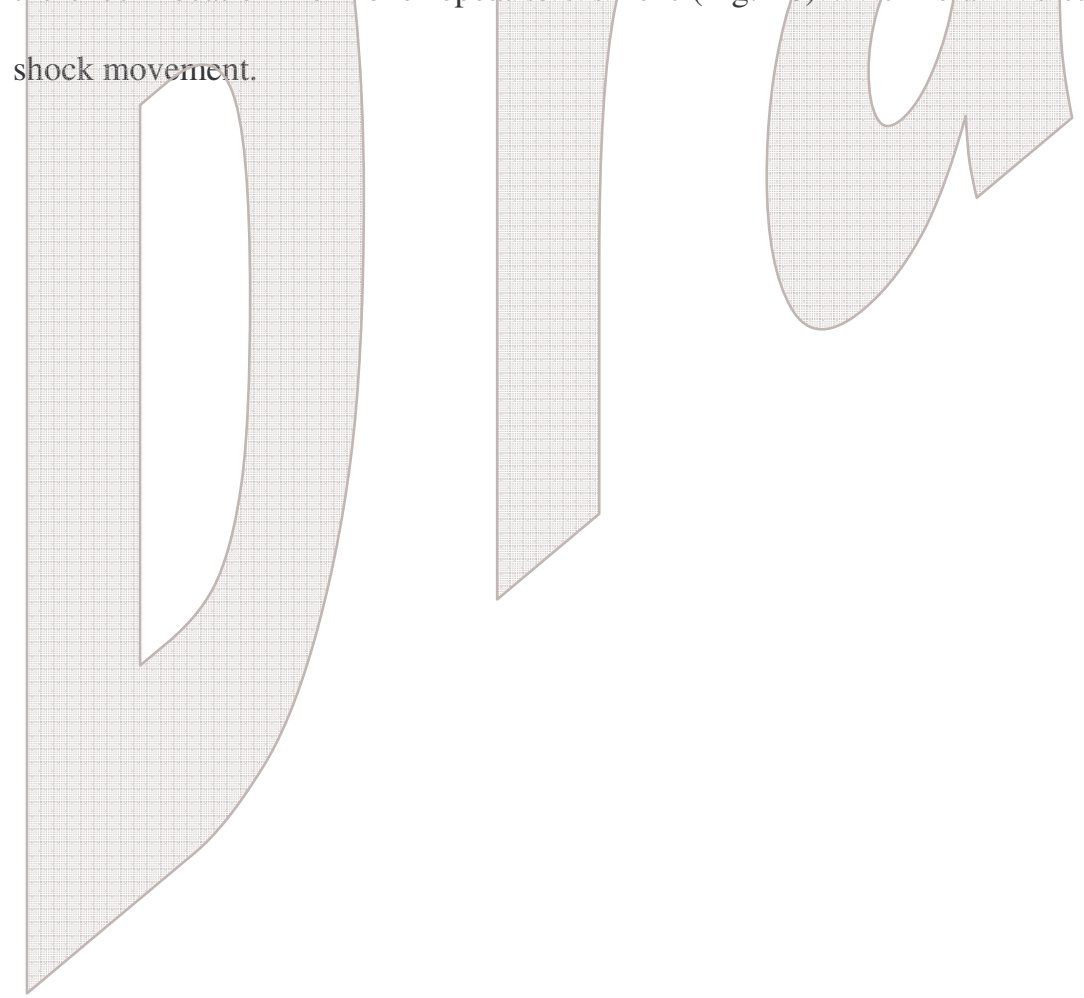

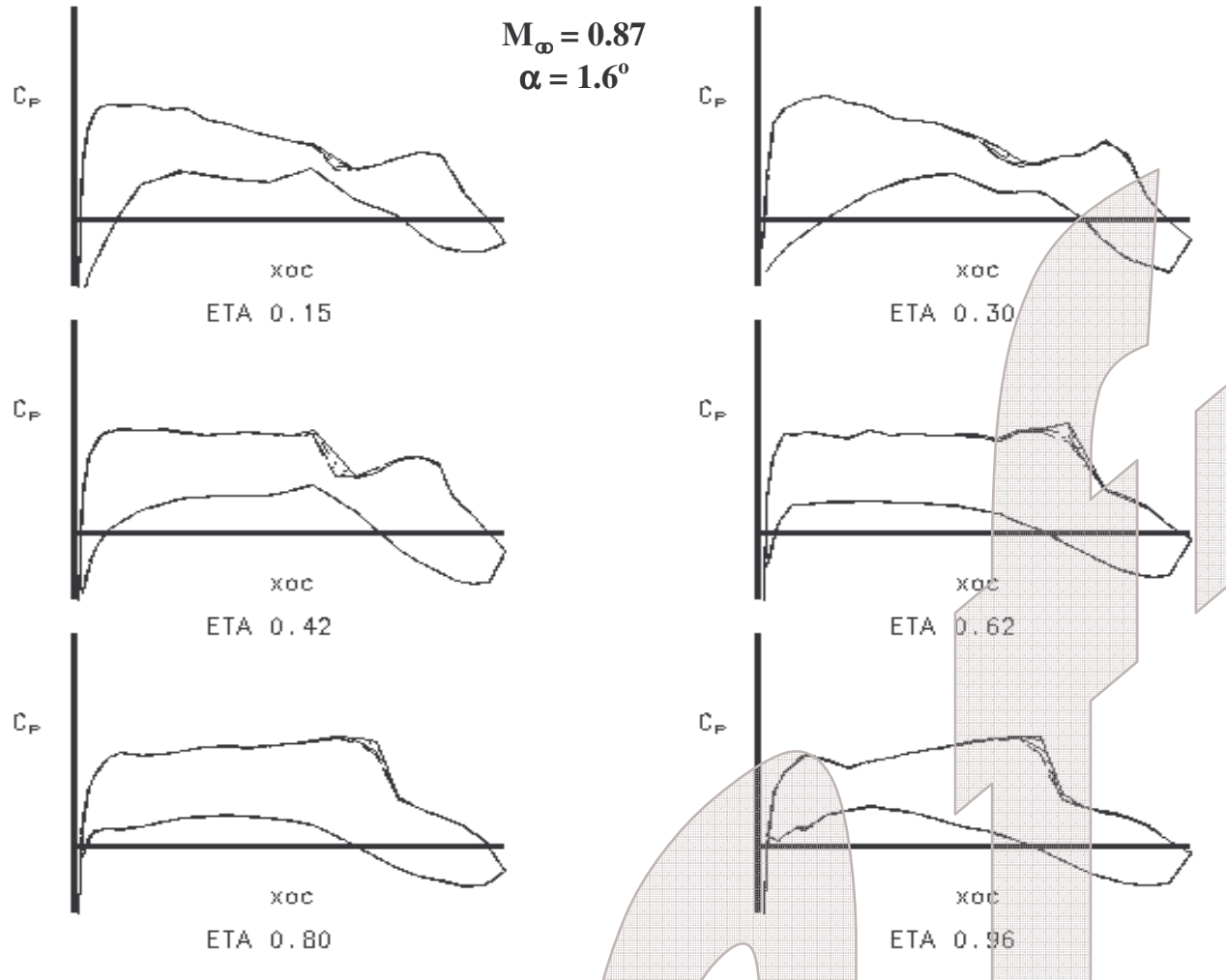

Fig. 20 Set of five repeats with speed taped ying local section $\mathbb{C}_{p}$ distributions verses xoc.

Once again, the data from the inflatabie bulb seal series were integrated into wing $\mathrm{C}_{\mathrm{n}}$ and $\mathrm{C}_{\mathrm{m}}$ and compared to the integrated data from the standard keel dam series. As from the previous test, these span load distributions at any given alpha show a similar small increase in the $\mathrm{C}_{\mathrm{n}}$ on the inboard wing with the model sealed to the floor that tapers away to no effect about three quarter span but with more variation from alpha to alpha on the outboard wing (Fig. $21 \mathrm{a}$ and $21 \mathrm{~b})$.

The integrated sectional data were linearized (Fig. 22a and 22b), rigidized and then corrected to derive wing slopes and intercepts at flight level Reynolds number (Re) (Fig.23a and 23b). These results are similar to that seen from the earlier testing with the exception of larger effects on the outboard wing. 


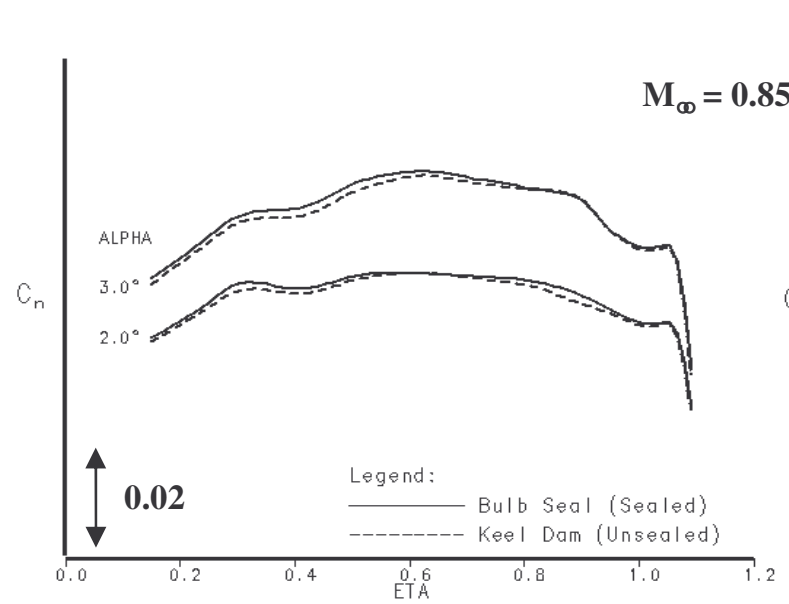

a)

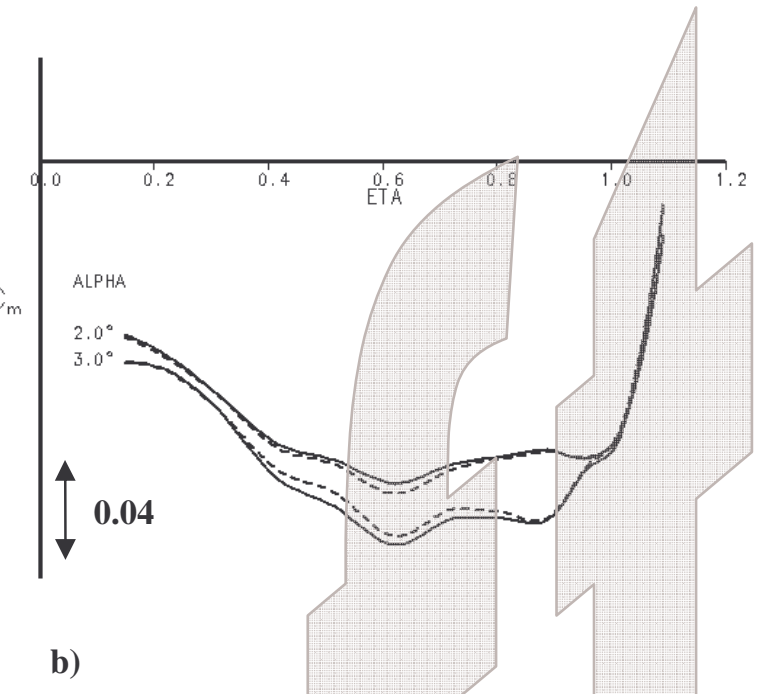

Fig. 21 a) Sealed and unsealed section normal force and b) pitching moment coefficient verses ETA.

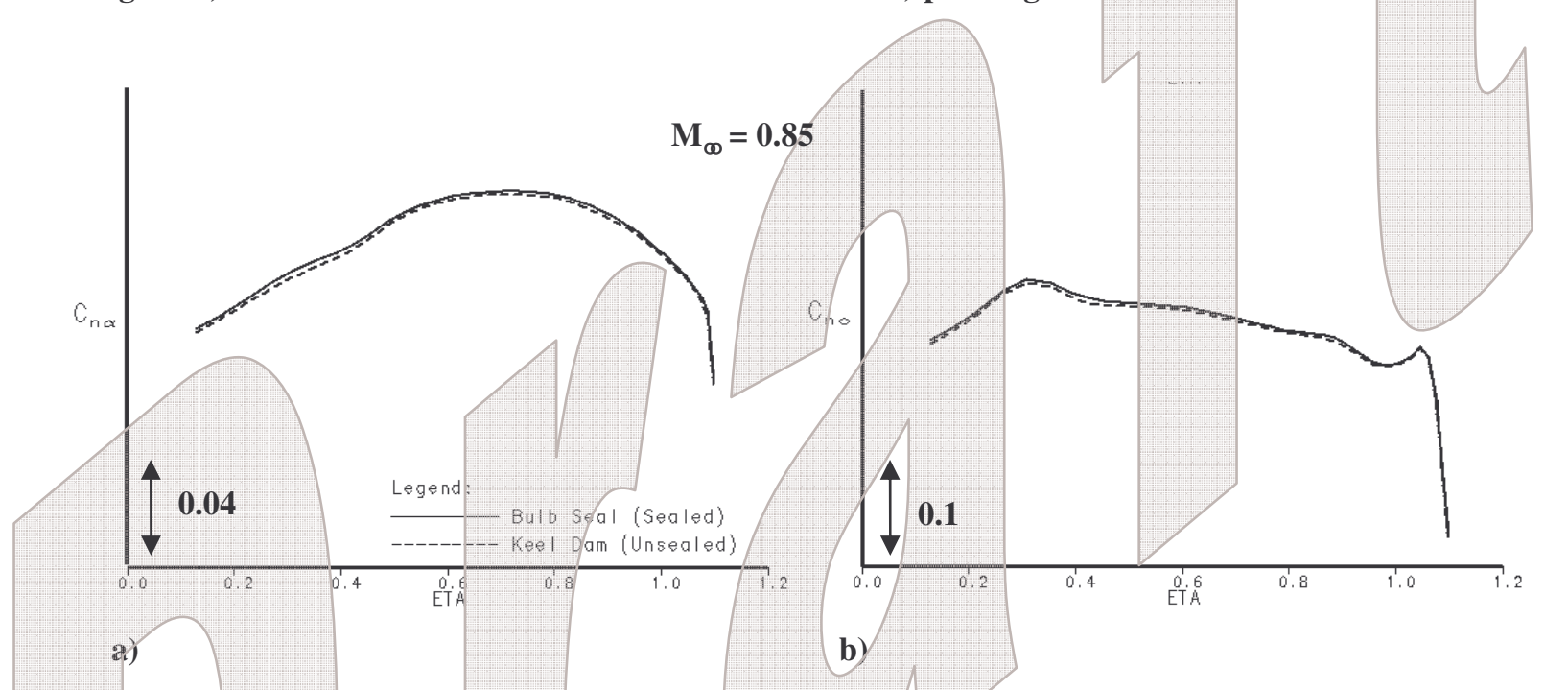

Fig. 22 a) Sealed and unsealed section normal force slope and b) intercept coefficient verses ETA.

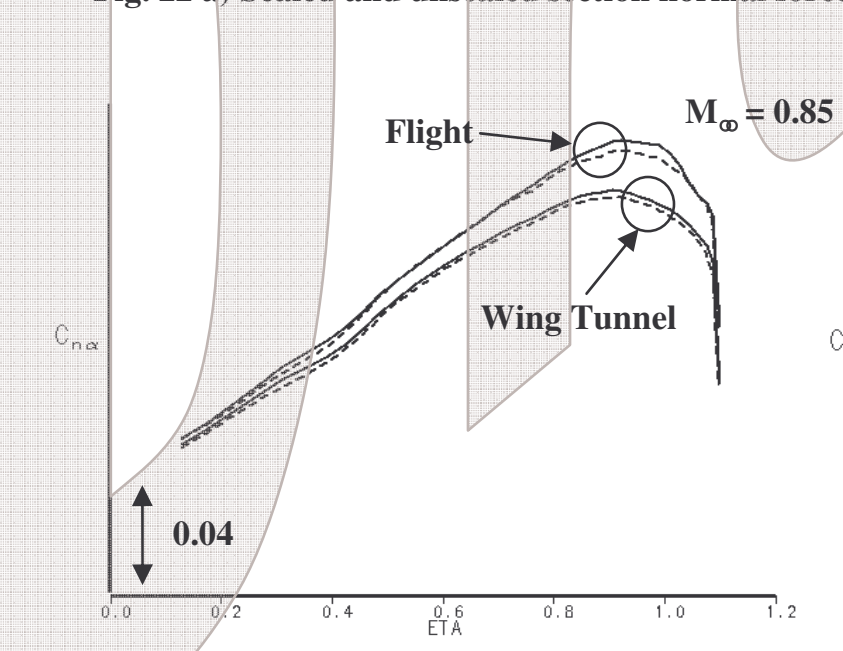

a)

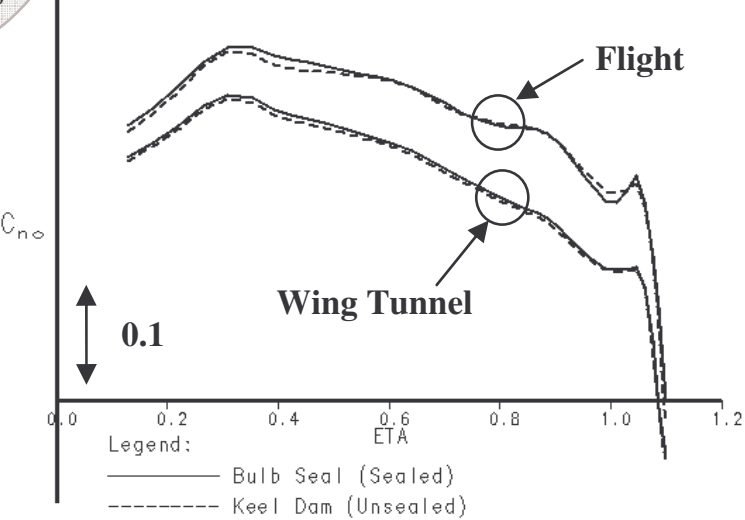

b)

Fig. 23 a) Sealed and unsealed rigid wind tunnel and extrapolated flight level section normal force slope and b) intercept coefficient verses ETA. 
For the sake of collecting balance total force and moment data consistent with the wing pressure data, the seal was inflated and deflated on back to back runs and to assess the viability of acquiring balance data with an inflatable seal installed. The balance data comparisons show that the inflated seal has a very small effect on the balance normal force (Fig.24a), a small but very likely non-trivial effect on the balance axial force(Fig.24b) and an obvious non-trivial effect on balance moments (Fig. 25a \& 25b). The differences are most likely due to fouling of the balance but additional effects may be due to the seal induced flow field changes.

a)

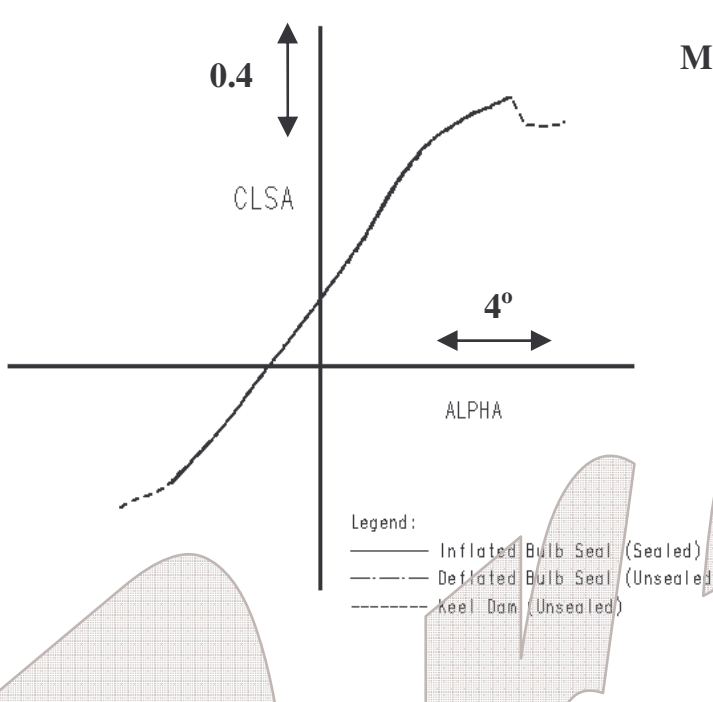

$$
\mathrm{M}_{\infty}=\mathbf{0 . 8 5}
$$

Fig. 24 a) Seal inflated, deflated and keel dam totai balance lift coefficient and b) total balance drag

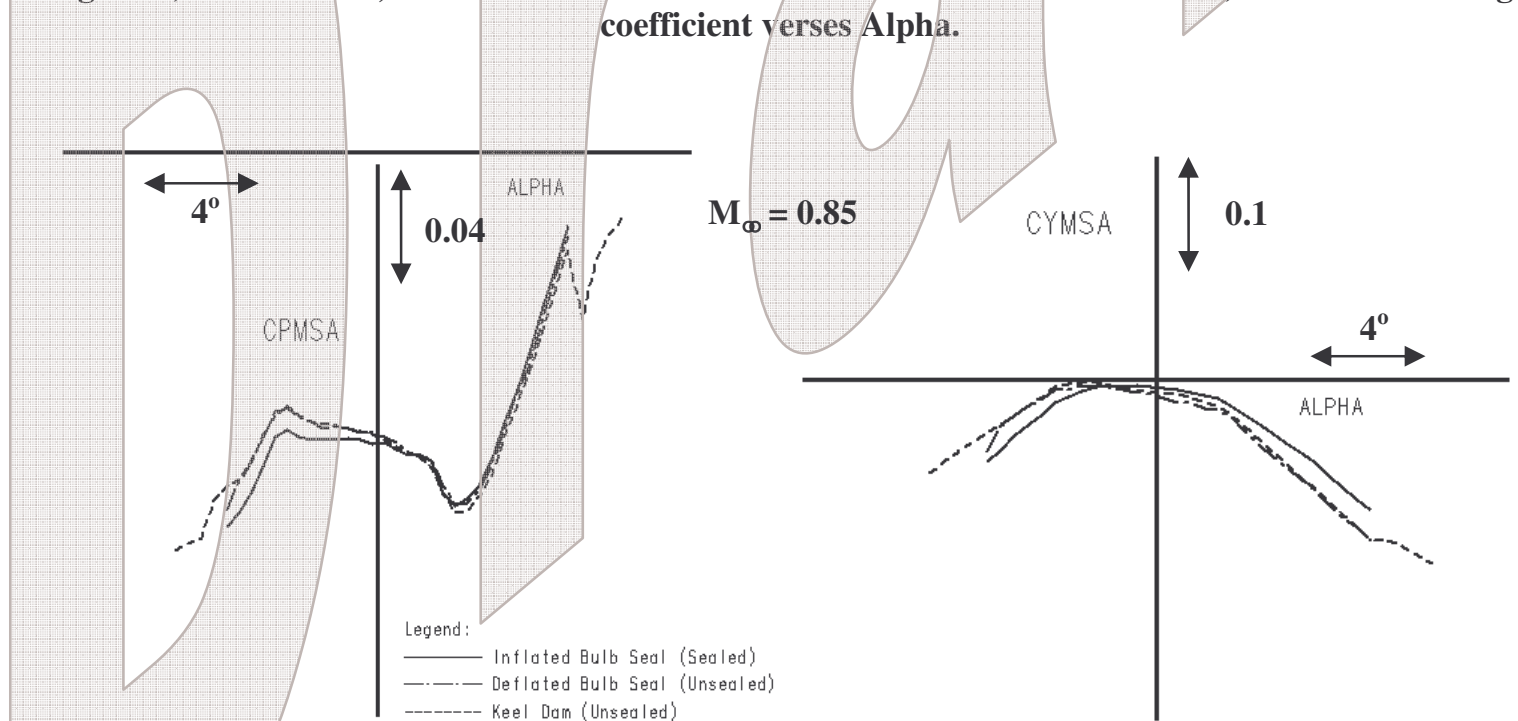

a)

b)

Fig. 25 a) Seal inflated, deflated and keel dam total balance pitching moment coefficient and b) total balance yawing moment coefficient verses Alpha. 


\section{Discussion}

\section{A. $\mathbf{C}_{\mathrm{p}}$ Data}

The standard keel dam data shows double shocks with first shock moved forward and a high recovery $\mathrm{C}_{\mathrm{p}}$. The taped series still shows double shocks but with shocks moving closer together and a lower recovery $\mathrm{C}_{\mathrm{V}}$. Looking at UV oil flow visualizations for spanwise behavior, the shocks begin to form inboard of the nacelle around 30-40\% chord, double up (20-30\% and 60-70\% chord) outboard of the nacelle, begin to converge on the mid wing and disappear near the tip (Fig. 26 and 27).

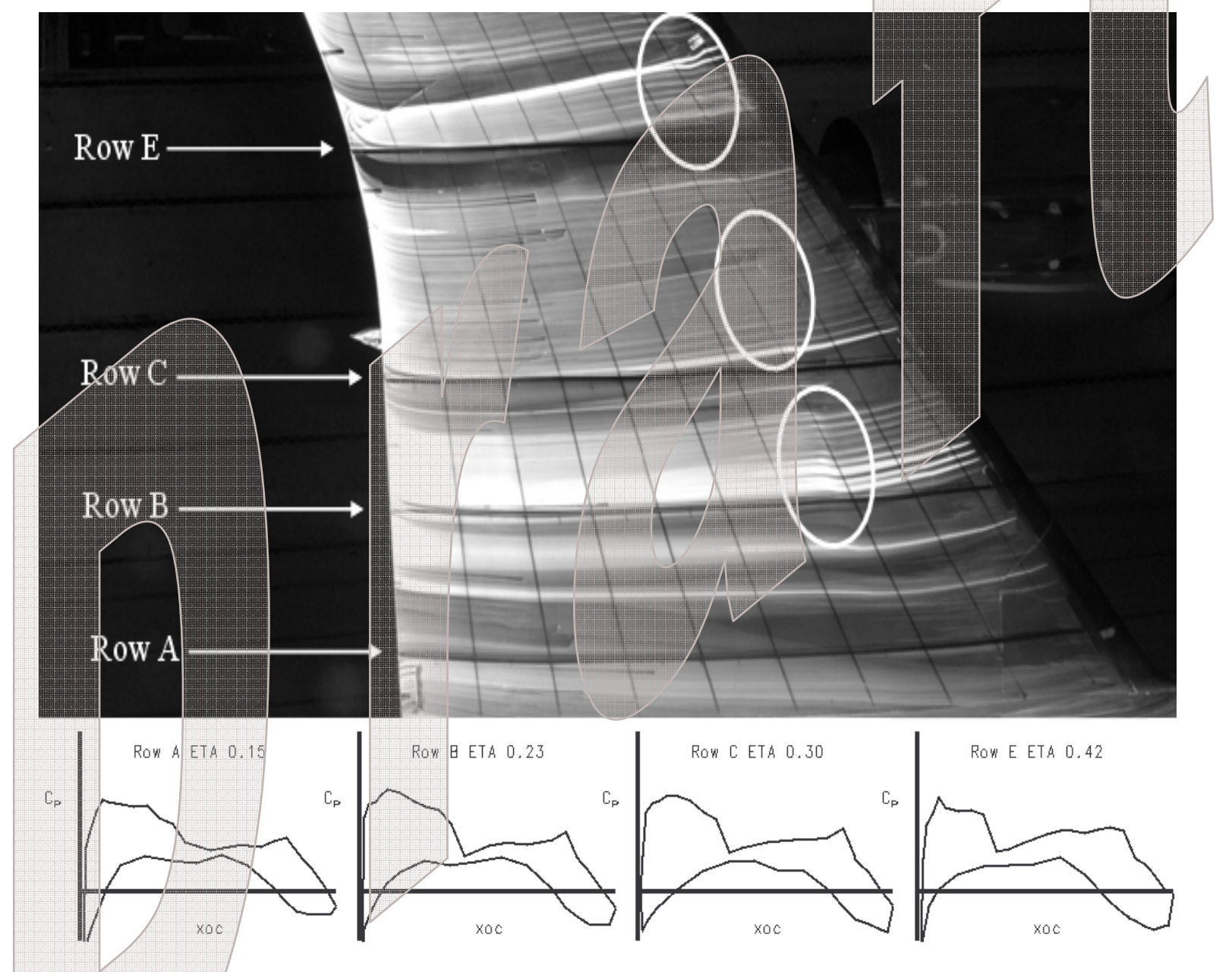

Fig. $26 \mathrm{UV}$ oil flow visualizations and local section $\mathrm{C}_{\mathrm{p}}$ distributions on inboard wing. 


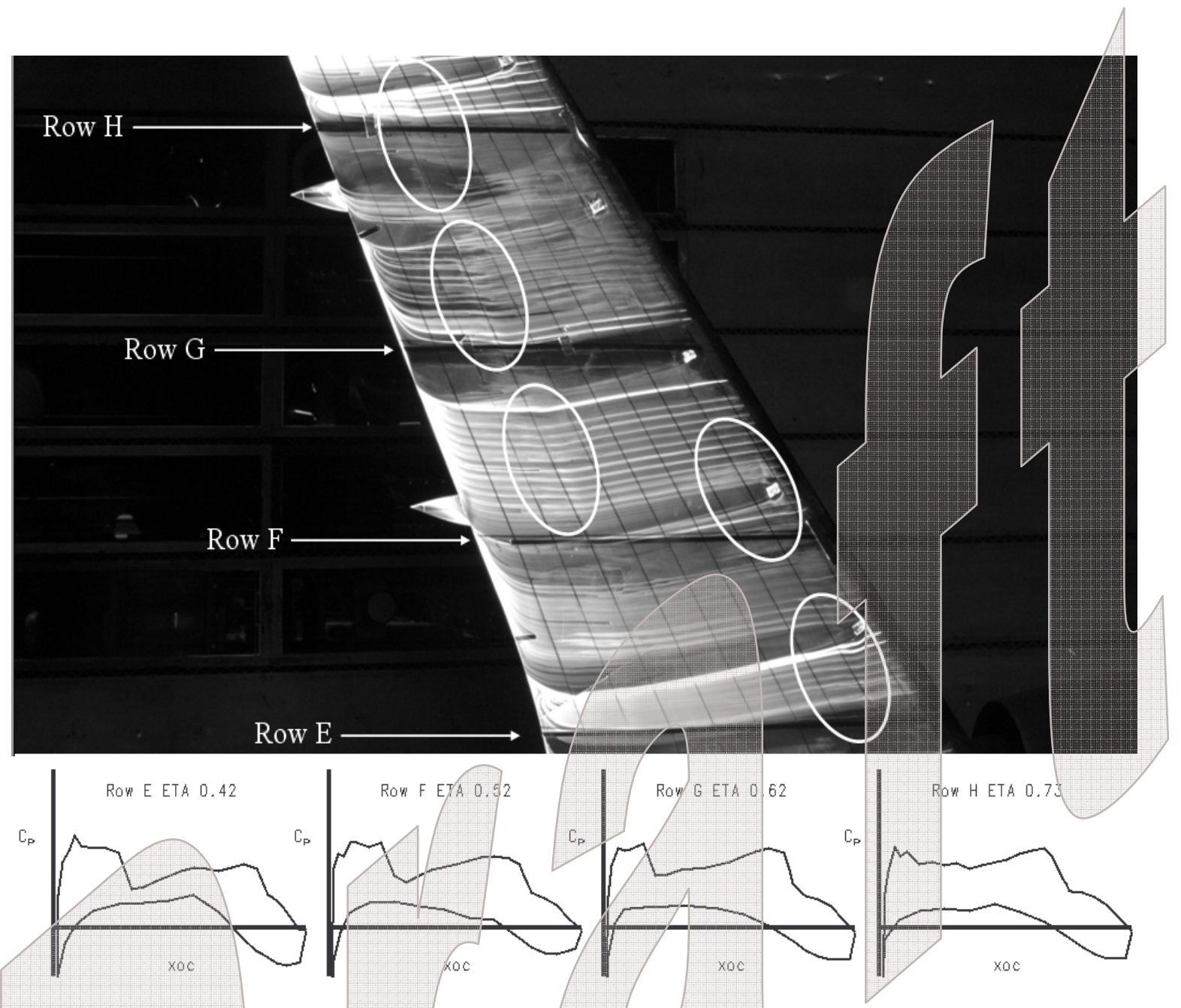

Fig. 27 UV oil flow visualizations and local section $C_{p}$ distributions on mid wing.

The inflated seal $\mathrm{C}_{\mathrm{p}}$ data looks similar to, though not exactly the same as, the taped data, but is quite different than the unsealed data. The deflated seal varies somewhat from test point to test point as to how well it inhibits flow under the model but largely the results show uninhibited flow. The taped series are our "best" tested data for addressing the seal effect as this method ensures complete inhibition of the flow but back to back repeats show a surprising sensitivity to shock movement. One possible reason for the sealed and taped differences could be that the inflatable seal layout is allowing for a "gutter" under the model that the flow can move into which is not realistic representation of full model flow. In any case, in the absence of shocks we see no difference in the results between any of the sealed and/unsealed techniques. 


\section{B. Integrated \& Linearized Data}

Test point to test point the integrated data appears very similar (shows no difference) between sealed and unsealed results with only a few alphas that show an effect from sealing. These alphas are dominating the slope changes and are primarily related to the large pressure differential associated with/strong shocks on the upper surface at high subsonic Mach numbers. For low Mach numbers and alphas that have no shocks or weak shocks, there is no significant change in the integrated or linearized data with the inflatable seal in place. Sealing results in a 1.5 to $3 \%$ increase in $\mathrm{C}_{\mathrm{n} \alpha}$ on the inboard wing over standard keel dam setup and diminishes to no effect by about $75 \%$ span. Similarly, $\mathrm{C}_{\mathrm{no}}$ for sealed runs increases on the inboard wing 1.5 to $2 \%$ over the unsealed result.

Larger than expected seal effects were seen on in the configuration $\mathrm{C}$ results on the outboard wing than were previously seen from the configuration A and B tests. Some reasons for the differences could be:

1. In-test repeatability issues as demonstrated the by shock movement $\left(C_{p}\right.$ variability at the shock location) on the taped to floor runs.

2. The model was very dynamic with the extended tip and this may have resulted in reduced consistency from run to run.

3. Differences in boundary layer effects of the walls and floor.

4. Linearization techniques used consistent alpha ranges to remove subjectivity, however subjectivity is still inherent in the linearization analysis process.

5. An actual effect of the model seal to the floor on this configuration.

\section{Reynolds Number Stretching}

This analysis required the reduction of three or more sets of aerodynamic test data, each at a specified Re, from which a linear log extrapolation on Re was derived to determine a flight Re set of data. The linearizations performed prior to the extrapolations used consistent alpha ranges to remove subjectivity but this analysis is still somewhat subjective. This can result in variations in the Re extrapolations with Mach number and span location of the change due to sealing that are; parallel (extrapolations are identical), converging or diverging. Because of these variations, it is difficult to discern a pattern due to sealing. The resulting extrapolations can, however, be adjusted to be more uniform and still be justified within the bounds of "consistent" linearizations. These resulting adjusted extrapolations show similar changes with floor sealing to that of the original linearized data. This indicates that the effects of floor sealing on Re extrapolations are within the accuracy and precision limitations of this analysis. 


\section{Force Data}

It was expected that the inflated seal would foul the balance and distort the force data. The force verses alpha plots show very little variation between the keel dam, inflated seal and deflated seal results while the moment plots show that the inflated seal results in an adverse effect. The differences are most likely due to fouling of the balance and seal induced flow field changes. A possible method to assess if the seal was fouling the balance would be to conduct a test wherein a static load is applied to the model with the wind off and the seal subsequently inflated and deflated. It appears that total force and moment data may be useful with the bulb seal inflatec, such as, when assessing global incremental effects.

We see that the inflatable seal makes a noticeable difference in the $C_{p}$ data and resulting linearizations. Inflated seal data are very similar to that of full perimeter taped runs, but less similar to that of standard keel dam runs. Data of deflated seals are in some cases very similar to that of taped rurs, but most often are similar to that from the keel dam runs. The effects of sealing to the floor on the Cp distributions are similar for all three configurations tested,

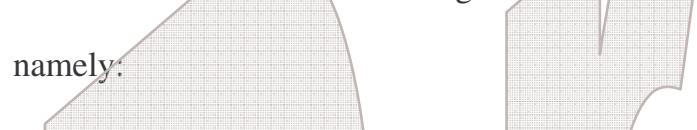

1. No effects in absence of shocks.

2. Shocks move aft with lower recovery with progressive sealing techniques.

3. Double shocks move closer together with progressive sealing techniques.

For all three configurations tested, linearized wing lift slopes and intercepts increased inboard about 1.5 to $3 \%$ and taper away outboard of mid-span. Some outboard differences seem to be due to outlying points in the linearizations. The Reynolds Number extrapolation differences are very likely within the uncertainty of the testing and data reduction process. The force data with the inflated seal may be acceptable; however the moment data shows sufficient differences compared to the unsealed data (fouling of the balance) which may preclude its usefulness except for incremental analysis.

Some ideas for possible follow-on studies are:

- Use CFD for modeling the floor and walls to determine what boundary layer effects may exist in the tunnel and whether double shocks are products of shocks reflecting off the floor/walls.

- Use CFD to model the floor gap to determine if CFD can duplicate the in tunnel empirical gap effect. 
- Use CFD for deriving corrections to the data collected from testing with the standard keel dam setup.

- Use comparisons of computed twists and deflections from the data reduction analysis to the values derived from in test photogrammetry to determine if model elastics are an issue.

- Investigate the development of calibration techniques to total balance data when testing with an inflated bulb seal.

\section{Acknowledgments}

We would like to acknowledgment from BCA ANP Labs; Dennis Hergert for being very instrumental throughout the investigation, Ron Watt for his work on the initjal concept, and Lee Cochran and Jeff Greene as the designers of the first and second inflatable bulb seal configurations, respectively. Wendy Lacy of BCA ANP Labs and Rene Hymmen of BCA Structures, Loads \& Dynamics for their managerial support throughout this effort. We are also grateful to William Carver of BCA Structures, Loads \& Dynamics for his historical prospective, guídance and wisdom. It was his original idea to seal by the simple, yet effective, method of taping the model to the floor.

${ }^{1}$ Goldhammer, M.E. and Steinle, F.W. Jr.: "Design and Validation of Advanced Transonic Wings Using CFD and Very High Reynolds Number Wind Tunnel Testing," Proceedings of the $17^{\text {th }}$ Intemational Council of the Aeronautical Sciences, Paper 902.6.2, Sept. 1990, pp. 1028-1042.

${ }^{2}$ Garriz, J A.; Newman P. A.; Vatsa, V. N.; Haigler, K. J., and Burdges, K. P.: "Evaluation of Transonic Wall Interference Assessment and Corrections for Semi-Span Wing Data," AIAA Paper 90-1433, $16^{\text {th }}$ Aerodynamic Ground Testing Conference, June 1990.

${ }^{3}$ Milholen, W. E, II and Chokani, N.: "Numerical Modeling of Transonic Juncture Flow," AIAA Paper 92-4036, 17 ${ }^{\text {th }}$ Aerodynamic Ground Testing Conference, July 1992.

${ }^{4}$ Gatlin, G. M1. and McGhee, R. J.: "A Study of Semi-Span Model Testing Techniques", AIAA Paper 96-2386, June 1996.

${ }^{5}$ Gatlin, G. M.; Parker P. A. and Owens, L. R. Jr.: "Advancement of a Semi-Span Testing at the National Transonic Facility," Journal of Aircraft, Vo1. 39, No. 2, 1997, pp. 339-353. 